\title{
Aves de la Reserva Nacional Isla Mocha, sur de Chile: Riqueza, abundancia y diversidad de especies
}

\section{Birds of Isla Mocha National Reserve, southern Chile: Species richness, abundance and diversity}

\author{
Carlos Riquelme ${ }^{1,2}$, Ana Hinojosa ${ }^{3}$, Ricardo A. Figueroa ${ }^{4}$ \& Daniel González-Acuña ${ }^{5 *}$
}

${ }^{1}$ Programa de Magíster en Ecología Aplicada, Instituto de Ciencias Ambientales y Evolutivas, Facultad de Ciencias, Universidad Austral de Chile, Chile.

2Programa de Investigación Aplicada en fauna Silvestre, Instituto de Ciencia Animal, Facultad de Ciencias Veterinarias, Universidad Austral de Chile, Chile.

${ }^{3}$ Departamento de Patrimonio Silvestre, Corporación Nacional Forestal, Chillán, Chile.

${ }^{4}$ Escuela de Graduados, Facultad de Ciencias Forestales y Recursos Naturales, Universidad Austral de Chile, Valdivia, Chile. ${ }^{5}$ Laboratorio de Parásitos y Enfermedades de Fauna Silvestre, Departamento de Ciencia Animal, Facultad de Ciencias Veterinarias, Universidad de Concepción, Chile.

*E-mail: danigonz@udec.cl

\section{RESUMEN}

Entre 2007 y 2008 evaluamos la riqueza, abundancia y diversidad estacional de aves en la Reserva Nacional isla Mocha, sur de Chile. Las aves fueron registradas en puntos de conteo (radio $=50 \mathrm{~m}$, duración $=10 \mathrm{~min}$ ) en cinco tipo de hábitats: borde costero, pastizal, pradera arbolada, ecotono bosque-pradera y bosque valdiviano. Para determinar mejor la riqueza de especies también incluimos registros ocasionales fuera de los puntos de conteo. La riqueza avifaunística en la isla alcanzó 70 especies. El hábitat más rico en especies fue el pastizal (29 especies), seguido del ecotono bosque-pradera y el borde costero ( 25 especies, respectivamente), la pradera arbolada (21 especies), y del bosque valdiviano (17 especies). No detectamos ningún patrón estacional al comparar las riquezas de especies entre hábitats. En todos los hábitats la distribución de abundancia entre las especies mostró el patrón típico de muchos organismos: pocas especies fueron muy abundantes o poco abundantes, y varias fueron medianamente abundante. Sin embargo, la dominancia numérica entre las especies cambió estacionalmente. Las especies más regulares fueron la gaviota dominicana en el borde costero y el pastizal, el queltehue en el pastizal, el jilguero en la pradera arbolada, la torcaza, el chucao y el rayadito en el ecotono bosque-pradera, y el chucao, rayadito y picaflor chico en el bosque valdiviano. Todas estas especies tuvieron fluctuaciones numéricas temporales notorias causadas posiblemente por el reclutamiento de individuos juveniles, migraciones, congregación reproductiva, y/o variación en la disponibilidad de alimento. Todos los hábitats tuvieron diversidades altas debido a que fueron ricos en especies y hubo una alta equitatividad entre especies respecto de su abundancia. En términos avifaunísticos la isla Mocha representa una "trozo" continental del sur de Chile, ya que la similitud en la diversidad de hábitats de esta isla con el continente resulta en ensambles similares de aves.

Palabras Claves: Áreas silvestres protegidas, distribución de abundancia, endemismo, islas oceánicas, modificación de hábitats.

\begin{abstract}
Between 2007 and 2008, we evaluated the seasonal richness, abundance and diversity of bird species in the Isla Mocha National Reserve, southern Chile. We recorded birds in point-count stations (radius $=50 \mathrm{~m}$, length $=10 \mathrm{~min}$ ) in five habitat types: coastline, pastureland, prairie with trees, forest-prairie ecotone, and Valdivian forest. We also include occasional records outside count points to determine species richness. In total, we recorded 70 species on the island. The habitat with higher species richness was the pastureland ( 29 species), followed by the forest-prairie ecotone, coastline ( 25 species, respectively), prairie with trees (21 species), and Valdivian forest (17 species). We did not detect seasonal patterns when we compared species richness among habitats. In all habitats, the abundance distribution among species showed the typical pattern of many organisms: few species were very or few abundant, and several had an intermediate abundance. However, the numerical dominance between species changed seasonally. The most regular species were Kelp Gull in the costline and pastureland, Chilean Lapwing in the pastureland, Black-chinned Siskin in the prairie with trees, Chilean Pigeon, Chucao Tapaculo and Thorn-tailed Rayadito in the forest-prairie ecotone, and Chucao Tapaculo, Thorn-tailed Rayadito, and Greenbacked Firecrown in the Valdivian forest. All these species showed noticeable seasonal numerical fluctuations possibly
\end{abstract}


caused by the recruitment of juveniles, reproductive congregation and/or variation in food availability. All habitats had a high diversity because they were rich in species and had high evenness among species regarding abundance. Avifaunally, the island Mocha represents a continental "slice" of southern Chile as the similarity in habitat diversity of this island to the mainland result in similar bird assemblages.

KeYwords: Abundance distribution, endemism, habitat modification, oceanic islands, protected areas.

\section{INTRODUCCIÓN}

Las islas oceánicas son reconocidas como centros importante de diversidad y endemismo de plantas y animales (Whittaker \& Fernández-Palacios 2007, Kier et al. 2009). Estas islas, particularmente en condición de archipiélago, constituyen sistemas modelos para desarrollar teorías biogeográficas, ecológicas y evolutivas fundamentales (e.g., teoría de biogeografía de islas; MacArthur \& Wilson 1967, Warren et al. 2014). El estudio de islas oceánicas per se es relevante en conservación biológica debido a su singularidad ecológica (Jackson et al. 2013). Aunque las islas oceánicas cercanas a los continentes tienden a ser menos diversas debido a la baja oportunidad de especiación (Péfaur \& Yáñez 1980), éstas pueden constituir reservorios de ecosistemas y biotas continentales amenazados (Quilhot et al. 2010).

La Isla Mocha, una isla oceánica cercana a Chile continental, forma parte del Sistema Nacional de Áreas Protegidas del Estado debido a que contiene remanentes de bosque valdiviano (Lequesne et al. 1999), alberga gran diversidad de aves terrestres y marinas (Péfaur \& Humphrey 1995), (iii) posee dos especies y tres subespecies endémicas de vertebrados (Philippi 1902, Bullock 1935, Hutterer 1994), y (iv) representa el sitio más importante de nidificación de la fardela blanca (Ardenna creatopus), una especie considerada vulnerable (Guicking et al. 1999, Ibarra-Vidal \& Klesse 1994, Hinojosa \& Hodum 2007, Conaf 2013). Por otra parte, después de la recolonización humana hace 160 años la isla ha sufrido una fuerte intervención antrópica. Actualmente, las principales amenazas para la avifauna de la isla son la presencia de perros, gatos y ratas asilvestradas (BirdLife International 2008, Conaf 2013).

Diversos estudios han evaluado la riqueza de aves en la Isla Mocha con resultados muy variables (68-102 especies; Cañas 1924, Housse 1924, 1925, Bullock 1935, Péfaur \& Yáñez 1980, Péfaur \& Humphrey 1995). Sin embargo, hasta ahora ningún estudio ha evaluado los cambios temporales en la comunidad de aves que habita la isla. Aquí, documentamos los resultados de un estudio realizado en la Isla Mocha cuyo objetivo fue evaluar las variaciones estacionales en la composición, riqueza y abundancia de aves.

\section{METODOLOGÍA}

Área DE ESTUDio

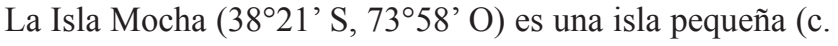
5200 ha) que está ubicada en el Océano Pacífico a 35 km frente a la desembocadura del río Tirúa, región del Biobío, en la costa del sur de Chile (Fig. 1). La parte plana de la

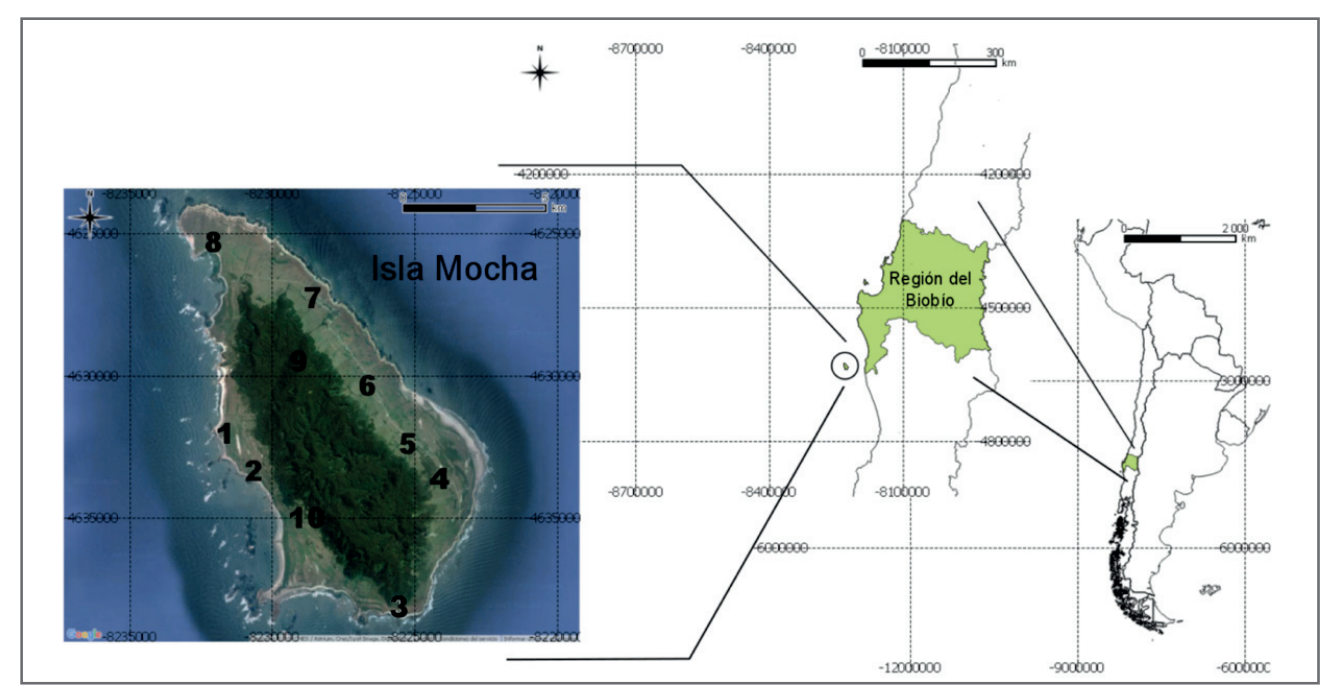

FIGURA 1. Ubicación de los puntos de conteo para estimar la composición, riqueza y abundancia de especies de aves en la Reserva Nacional Isla Mocha, sur de Chile, entre 2007 y 2008. Puntos de conteo: 1 y $2=$ borde costero, 3 y $10=$ ecotono bosque-pradera, 4 y $5=$ pradera arbolada, 6-8 = pastizal, y $9=$ bosque valdiviano. / Location of counting points used to estimate composition, richness, and abundance of avian species in Isla Mocha National Reserve, southern Chile, between 2007 and 2008. Counting points: 1 and $2=$ coastline, 3 and $10=$ forest-grassland ecotone, 4 and $5=$ prairie with trees, $6-8=$ pastureland, and $9=$ Valdivian forest. 
isla está ocupada por una comunidad residente de c. 700 personas, repartida en 32 predios. Esta comunidad mantiene una economía de subsistencia que incluye faenas agrícolas, ganaderas y pesqueras (Hinojosa \& Hodum 2007, Guicking et al. 1999).

La isla se caracteriza topográficamente por tener una extensa zona plana alrededor de toda su periferia y por la existencia de dos cordones montañosos relativamente altos (300-390 m s.n.m.) en la parte central. Actualmente, cuatro tipos vegetacionales son claramente distinguibles: (i) vegetación litoral, constituida por plantas anuales y matorrales perennes de baja altura adaptados al viento y condiciones salinas; (ii) praderas agrícolas, constituidas básicamente por gramíneas y leguminosas que sirven de sustento a la masa ganadera; (iii) matorral esclerófilo, compuesto principalmente de boldo (Peumus boldus), maqui (Aristotelia chilensis) y quebracho (Cassia estipulacea). Estos matorrales son el resultado de la fuerte degradación del bosque esclerófilo original que existía en la isla (Verdugo 1988); y (iv) bosque valdiviano. Al igual que en el continente, este bosque posee una alta diversidad vegetal (Kunkel 1968, Péfaur \& Yáñez 1980, Verdugo 1988). La flora arbórea está constituida principalmente por olivillo (Aextoxicon punctatum) acompañado de lingue (Persea lingue), ulmo (Eucryphia cordifolia), arrayán (Luma apiculata), pitra (Myrceugenia planipes), luma (Amomyrtus luma), tepa (Laurelia philippiana), melí (Amomyrtus meli), laurel (Laurelia sempervirens), canelo (Drimys winteri), tiaca (Caldcluvia paniculata) y sauco del diablo (Pseudopanax laetevirens). Las especies del género Nothofagus están ausente en la Isla Mocha (Péfaur \& Yáñez 1980). Los helechos están representados por al menos 37 especies los que conforman gran parte del sotobosque (Kunkel 1968). Las praderas agrícolas y matorrales están localizados entre la franja litoral y la zona montañosa, y el bosque valdiviano ocupa toda la zona montañosa.

El clima de la isla se caracteriza por una fuerte influencia oceánica con temperaturas mínimas y máximas medias anuales de $9,4^{\circ}$ y $15,5^{\circ} \mathrm{C}$, humedad promedio cercana al $85 \%$ y precipitaciones promedio de $1317 \mathrm{~mm}$ (Hajek \& Di Castri 1975).

\section{DISEÑO DE MUESTREO}

Entre 2007 y 2008 realizamos conteos estacionales de aves en cinco tipos de hábitats de la isla, los cuales definimos como sigue: (i) borde costero o litoral, (ii) pastizal, (iii) pradera arbolada, (iv) ecotono bosque-pradera, y (v) bosque. Las características de estos hábitats son detallados en la Tabla 1. Los conteos fueron realizados en la primavera de 2007 (14-19 de septiembre), y en el verano (29 de enero-3 de febrero), otoño (27 de abril-2 de mayo) y primavera (1116 de diciembre) de 2008. Los conteos fueron hechos en puntos seleccionados aleatoriamente sobre la base de un mapa cuadriculado. Cada cuadrícula representó un área de
$250.000 \mathrm{~m}^{2}$. El número de puntos dentro de cada tipo de hábitat fue el siguiente: tres en el pastizal, dos en el borde costero, la pradera arbolada y el ecotono bosque-pradera, y uno en el interior del bosque (Fig. 1).

En cada punto de conteo, registramos todas las aves vistas y escuchadas en un radio de $50 \mathrm{~m}$, y tomando los datos durante 10 minutos (Sutherland 1996). Por razones logísticas, el horario de conteo difirió entre puntos de conteo (Tabla 1). No obstante, el mismo horario fue mantenido en cada punto durante todas las estaciones. Dos conteos por punto fueron realizados en cada estación. Las observaciones fueron hechas a ojo desnudo o con el apoyo de binoculares $(12 \times 25)$ cuando fue necesario.

\section{RESTRICCIONES METODOLÓGICAS}

Cabe reconocer que la cantidad de puntos de conteos en cada tipo de hábitat es pequeña, y que los horarios de conteo no fueron los mismos para todos los hábitats. Estas restricciones metodológicas fueron el resultado de limitaciones logísticas y el tiempo limitado de estadía en la isla. Tales restricciones pudieron haber sesgado la detectabilidad en el número de especies y cantidad de individuos. De esta manera, nuestro estudio debe ser considerado una aproximación preliminar sobre la comunidad de aves de la isla Mocha.

\section{ANÁLISIS DE LA INFORMACIÓN}

La diversidad avifaunística en cada tipo de hábitat fue evaluada según la composición taxonómica, riqueza y abundancia relativa de especies, fluctuación numérica estacional, y diversidad proporcional. La identidad taxonómica siguió la nomenclatura propuesta por Remsen et al. 2013. La riqueza fue definida simplemente como el número total de especies registradas. La abundancia relativa de cada especie fue estimada de la manera siguiente: $\mathrm{AR}=$ $\left(\mathrm{N}^{\circ}\right.$ de individuos de la especie $i / \mathrm{N}^{\circ}$ total de individuos de todas la especies) x 100. La fluctuación numérica estacional fue evaluada para las seis especies más frecuente dentro de cada tipo de hábitat. Para esto, estimamos el número medio de individuos de una especie en cada estación climática sobre la base del número de individuos registrados en cada punto de conteo. La amplitud numérica intra-estacional de cada especie fue representada por el número mínimo y máximo de individuos registrados dentro de los puntos de conteo. La diversidad proporcional de aves fue calculada usando el índice de diversidad recíproco de Simpson $\left(\mathrm{C}_{\mathrm{inv}}\right.$; Krebs 1989). Este índice fue preferido por dos razones. Primero, el cálculo de $\mathrm{C}_{i n v}$ es menos sensible al número de especies, $S$. A menudo, $S$ es un artefacto del diseño o esfuerzo de muestreo (Feinsinger 2001). En nuestro caso, el bajo número de puntos de conteo pudo haber sesgado negativamente la detección de especies. Segundo, $\mathrm{C}_{i n v}$ es más fácil de interpretar ya que su valor representa la cantidad de especies más equitativamente repartidas respecto del número de individuos (Feinsinger 2001). 
Aves de la Isla Mocha: Riquelme, C. ET AL.

TABLA 1. Características de los hábitats muestreados para estimar la composición, riqueza y abundancia de especies de aves en la Reserva Nacional Isla Mocha, sur de Chile, entre 2007 y 2008. La información de las características vegetacionales fue obtenida de Lequesne \& Meyer (1990). / Characteristics of the habitats sampled to estimate the composition, richness and abundance of bird species in the Isla Mocha National Reserve, southern Chile, between 2007 and 2008. Information regarding vegetation was obtained from Lequesne \& Meyer (1990).

\begin{tabular}{|c|c|c|c|}
\hline Tipo de HÁbitat & CARACTERÍSTICAS & $\mathrm{N}^{\circ}$ Puntos de Conteo & Horario de Muestreo \\
\hline Borde costero & $\begin{array}{l}\text { Playa rocosa o arenosa cercana a } \\
\text { matorrales y/o pastizales. Las especies } \\
\text { vegetales dominantes son Ambrosia } \\
\text { chamissonis, Panicum urvilleanium, } \\
\text { Margycarpus pinnatus, Eryngium } \\
\text { paniculatumy Euphobia portulacoides } \\
\text { entre otras. }\end{array}$ & 2 & 08:00-10:00 \\
\hline Pastizal & $\begin{array}{l}\text { Pastizales de gramíneas cerca del } \\
\text { borde costero o al interior de la isla. } \\
\text { Las especies de pastos dominantes } \\
\text { son Cynosurus echinatus, Bromus } \\
\text { unioloides y Melitotus indica. } \\
\text { Presencia de ganado doméstico. }\end{array}$ & 3 & $11: 00-14: 00$ \\
\hline Pradera arbolada & $\begin{array}{l}\text { Praderas ganaderas o agrícolas con } \\
\text { presencia de árboles y arbustos los } \\
\text { cuales incluyen especies esclerófilas } \\
\text { nativas (e.g. Boldo, Arrayán, Olivillo, } \\
\text { Quebracho, Natre) y especies } \\
\text { introducidas (Hordeum murinum, B. } \\
\text { unioloides). }\end{array}$ & 2 & $10: 30-12: 30$ \\
\hline Ecotono bosque-pradera & $\begin{array}{l}\text { Zona entre los bordes de bosque y } \\
\text { praderas arboladas, similares a las } \\
\text { praderas arboladas mencionadas } \\
\text { anteriormente, pero con un grado de } \\
\text { fragmentación menor. }\end{array}$ & 2 & 07:30-09:00 \\
\hline Bosque valdiviano & $\begin{array}{l}\text { Vegetación de desarrollo secundario, } \\
\text { conformado principalmente por } \\
\text { olivillo y arrayán. Con árboles altos } \\
\text { y sotobosque denso compuesto de } \\
\text { Megalastrum spectabilis, Luzuriaga } \\
\text { radicans y Pseudopanax valdiviensis. }\end{array}$ & 1 & $15: 30$ \\
\hline
\end{tabular}

TABLA 2. Riqueza estacional y anual de especies de aves en cinco tipos de hábitats de la Reserva Nacional Isla Mocha, región del Bío-Bío, sur de Chile. / Seasonal and annual bird species richness in five types of habitat of Isla Mocha National Reserve, Bío-Bío Region, southern Chile.

\begin{tabular}{lccccc}
\hline & PrimaVera 2007 & Verano 2008 & $\begin{array}{c}\text { OTOÑO } \\
2008\end{array}$ & InVIERno 2008 & $\begin{array}{c}\text { Todas LAS } \\
\text { ESTACIONES }\end{array}$ \\
\hline Borde costero & 12 & 16 & 11 & 12 & 25 \\
Pastizal & 20 & 17 & 15 & 21 & 29 \\
Pradera arbolada & 18 & 16 & 14 & 13 & 21 \\
Ecotono bosque-pradera & 20 & 18 & 16 & 21 & 25 \\
Bosque valdiviano & 15 & 14 & 32 & 33 & 17 \\
Todos los hábitats & 40 & 37 & & & \\
\hline
\end{tabular}




\section{RESULTADOS}

COMPOSICIÓN Y RIQUEZA TOTAL DE ESPECIE

Un total de 46 especies fueron registradas durante todo el periodo de estudio en la isla Mocha. Diez de las especies registradas son de ambientes costero-oceánicos y las 36 restantes son de tipo continental [ver Apendice 1]. Fuera de los puntos de conteo, registramos 24 especies adicionales (ver Apendice 1).

RiQUEZA DE ESPECIES POR HÁBITAT Y ESTACIÓN CLIMÁTICA El tipo de hábitat más rico en especies fue el pastizal, seguido del ecotono bosque-pradera, borde costero, la pradera arbolada, y del bosque valdiviano (Tabla 2). La primavera $\mathrm{y}$ el invierno fueron las estaciones en las que registramos más y menos especies, respectivamente (Tabla 2). Ningún patrón estacional fue detectado al comparar la riqueza entre hábitats. Mientras en el pastizal y el ecotono bosque-pradera la riqueza fue tan alta en primavera como en invierno, en la pradera arbolada y el bosque valdiviano tendió a disminuir hacia el invierno, y en el borde costero sólo mostró un alza durante el verano (Tabla 2).
COMPOSICIÓN Y ABUNDANCIA PROPORCIONAL DE ESPECIES

En todos los hábitats el patrón de distribución de abundancia entre las especie fue muy similar (Fig. 2-6). Sin embargo, la dominancia numérica entre las especies más frecuentes cambió estacionalmente. En el borde costero, la gaviota dominicana (Larus dominicanus), el zarapito (Numenius phaeopus), el piquero (Sula variegata) y el queltehue (Vanellus chilensis) intercambiaron o compartieron su dominancia numérica entre las distintas estaciones climáticas (Fig. 7).

En el pastizal, las especies más numerosas a lo largo de todas las estaciones climáticas fueron el queltehue, la gaviota dominicana, el tiuque (Milvago chimango) y el jote cabeza colorada (Cathartes aura). Sin embargo, durante el otoño la gaviota cahuil (Chroicocephalus maculipennis) mostró un alza numérica considerable con relación a las otras especies (Fig. 8). En la pradera arbolada, el jilguero (Spinus barbata) y la torcaza (Patagioenas araucana) tendieron a ser las especies más abundantes a lo largo del año, intercambiando su dominancia numérica en algunas estaciones (Fig. 9). Cabe destacar también que en otoño y en invierno, la bandurria (Theristicus melanopis) y el tiuque estuvieron entre las especies más abundantes, respectivamente.

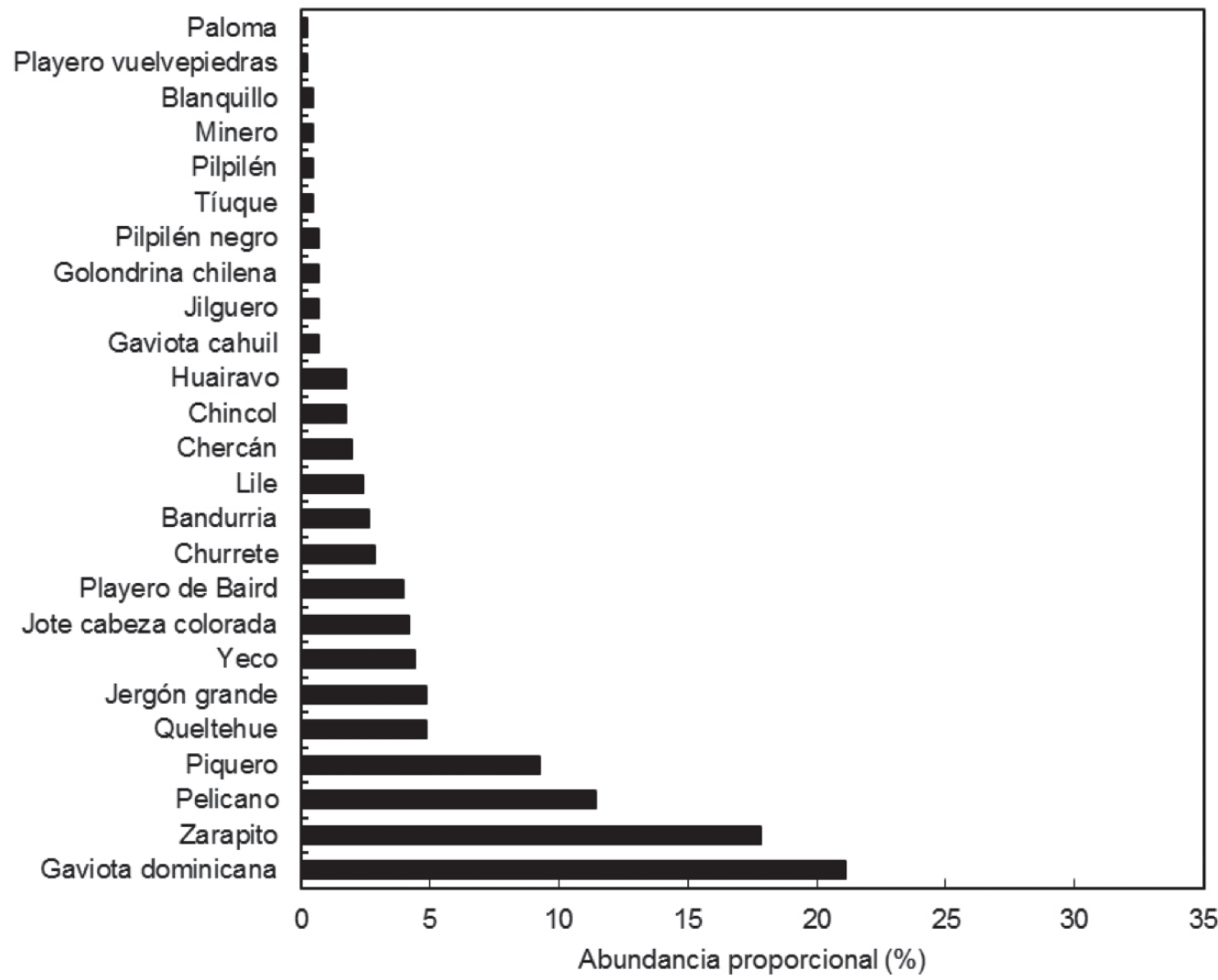

FIgURA 2. Composición y abundancia proporcional anual de aves en el borde costero de la Reserva Nacional Isla Mocha, sur de Chile (20072008). / Annual composition and relative abundance of birds in the coastline of Isla Mocha National Reserve, southern Chile (2007-2008). 


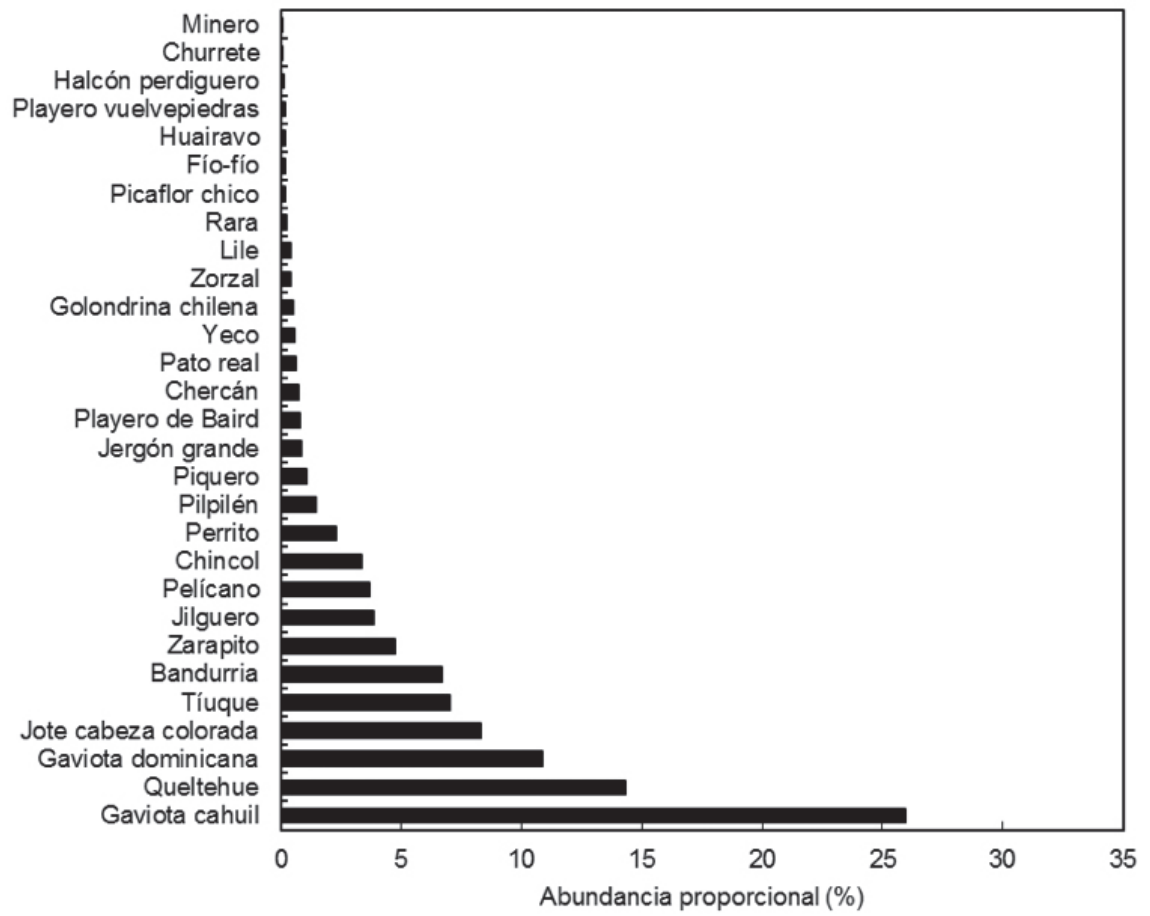

Figura 3. Composición y abundancia proporcional anual de aves en el pastizal de la Reserva Nacional Isla Mocha, sur de Chile (20072008). / Annual composition and relative abundance of birds in the pastureland of Isla Mocha National Reserve, southern Chile (20072008).

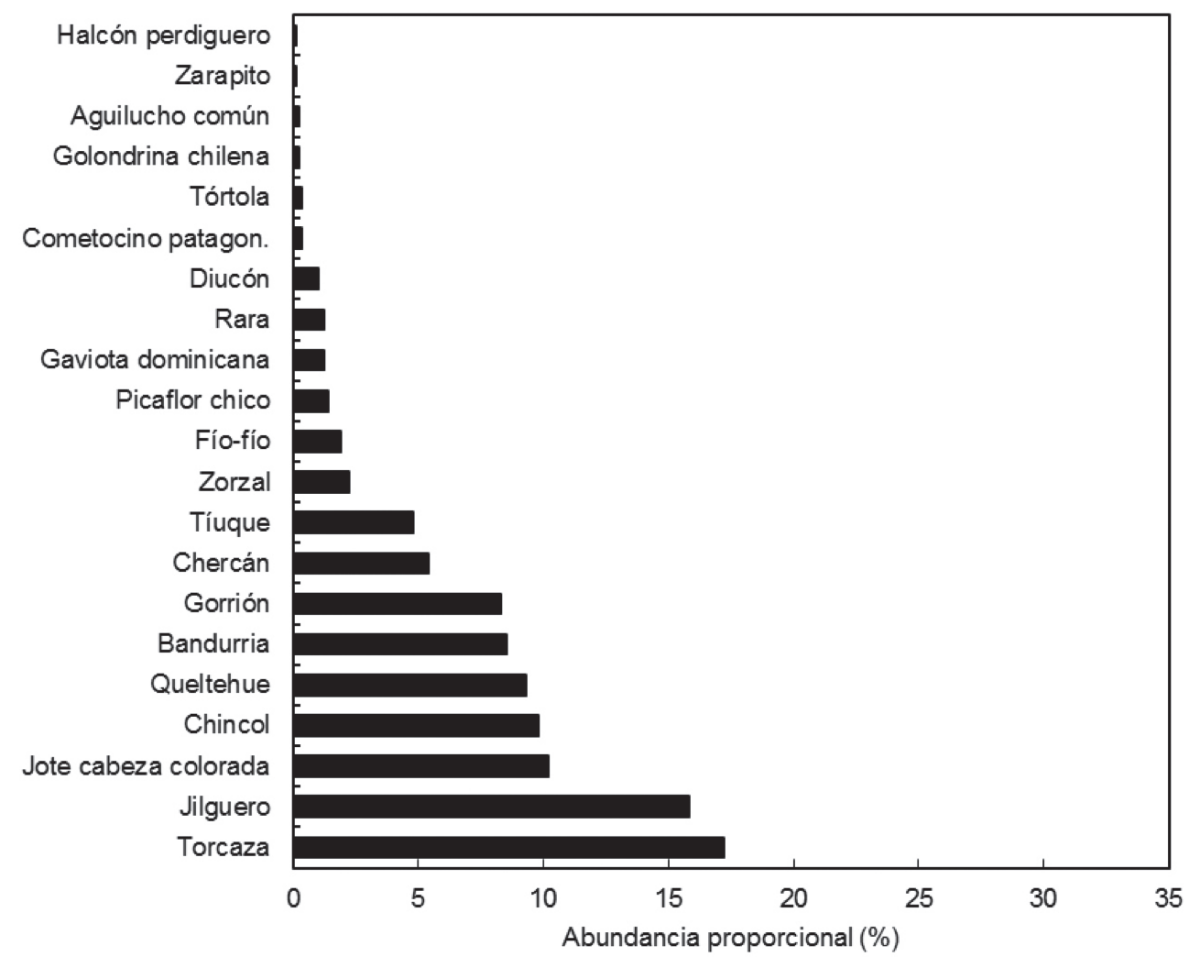

FiguRA 4. Composición y abundancia proporcional anual de aves en la pradera arbolada de la Reserva Nacional Isla Mocha, sur de Chile (2007-2008). / Annual composition and relative abundance of birds in the prairie with trees of Isla Mocha National Reserve, southern Chile (2007-2008). 
Gayana 82(1), 2018

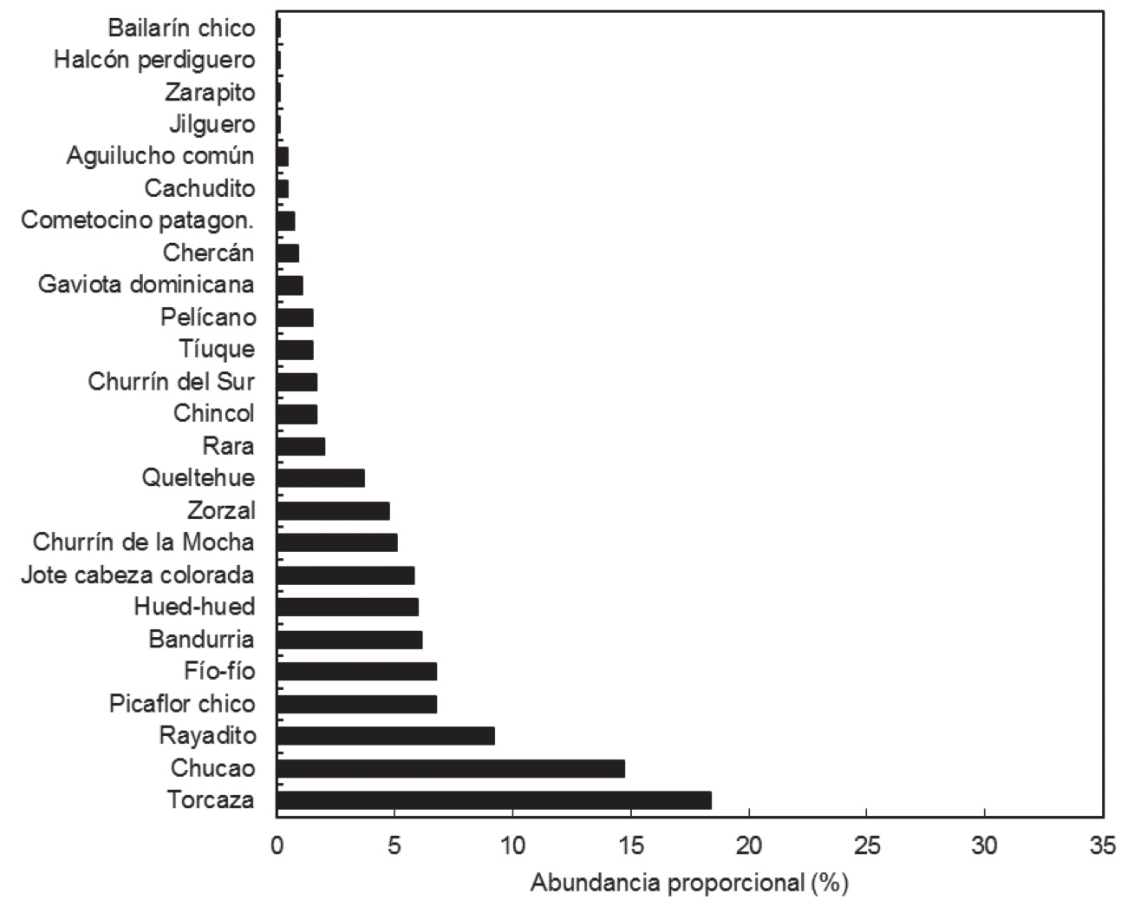

FiguRA 5. Composición y abundancia proporcional anual de aves en el ecotono bosque-pradera de la Reserva Nacional Isla Mocha, sur de Chile (2007-2008). / Annual composition and relative abundance of birds in the forest-grassland ecotone in Isla Mocha National Reserve, southern Chile (2007-2008).

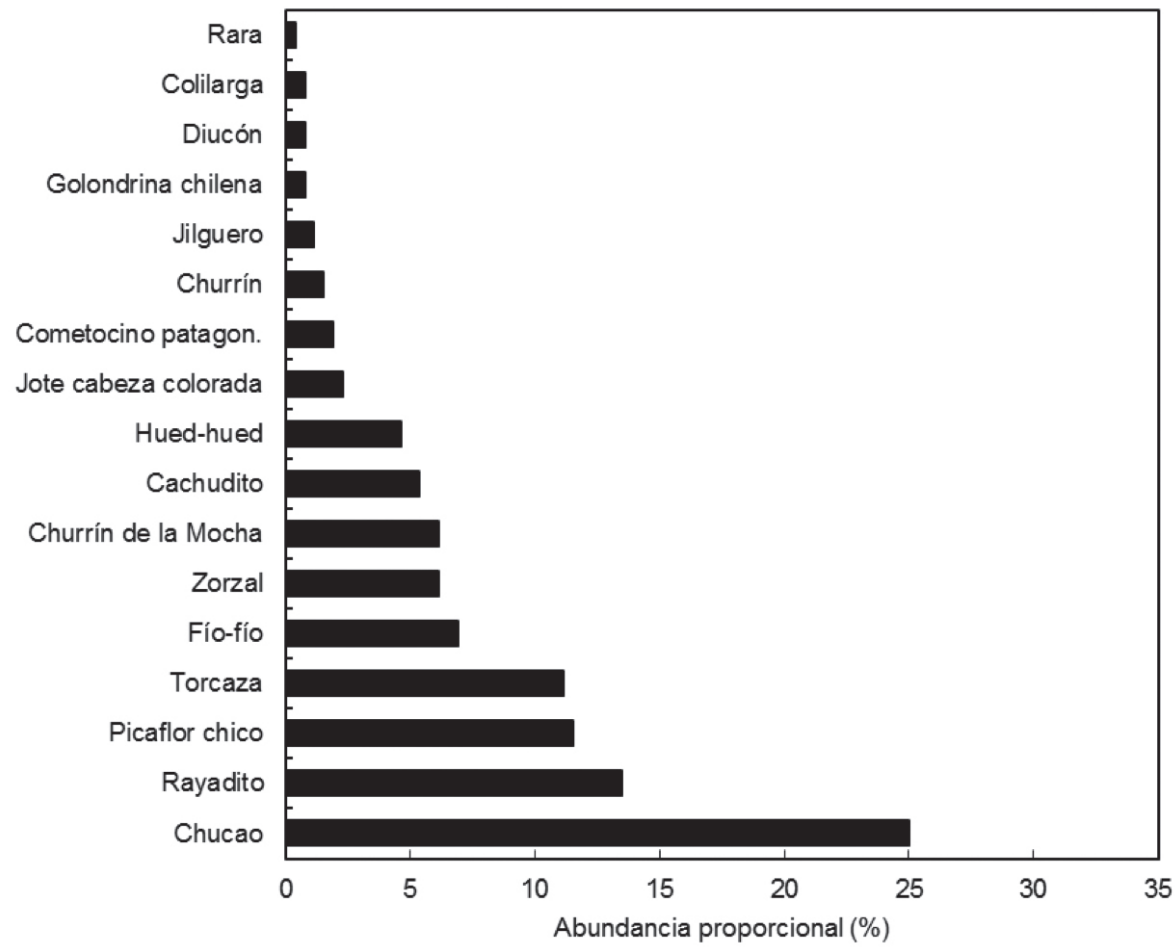

Figura 6. Composición y abundancia proporcional anual de aves en el bosque valdiviano de la Reserva Nacional Isla Mocha, sur de Chile (2007-2008). Annual composition and relative abundance of birds in the Valdivian forest of Isla Mocha National Reserve, southern Chile (2007-2008). 

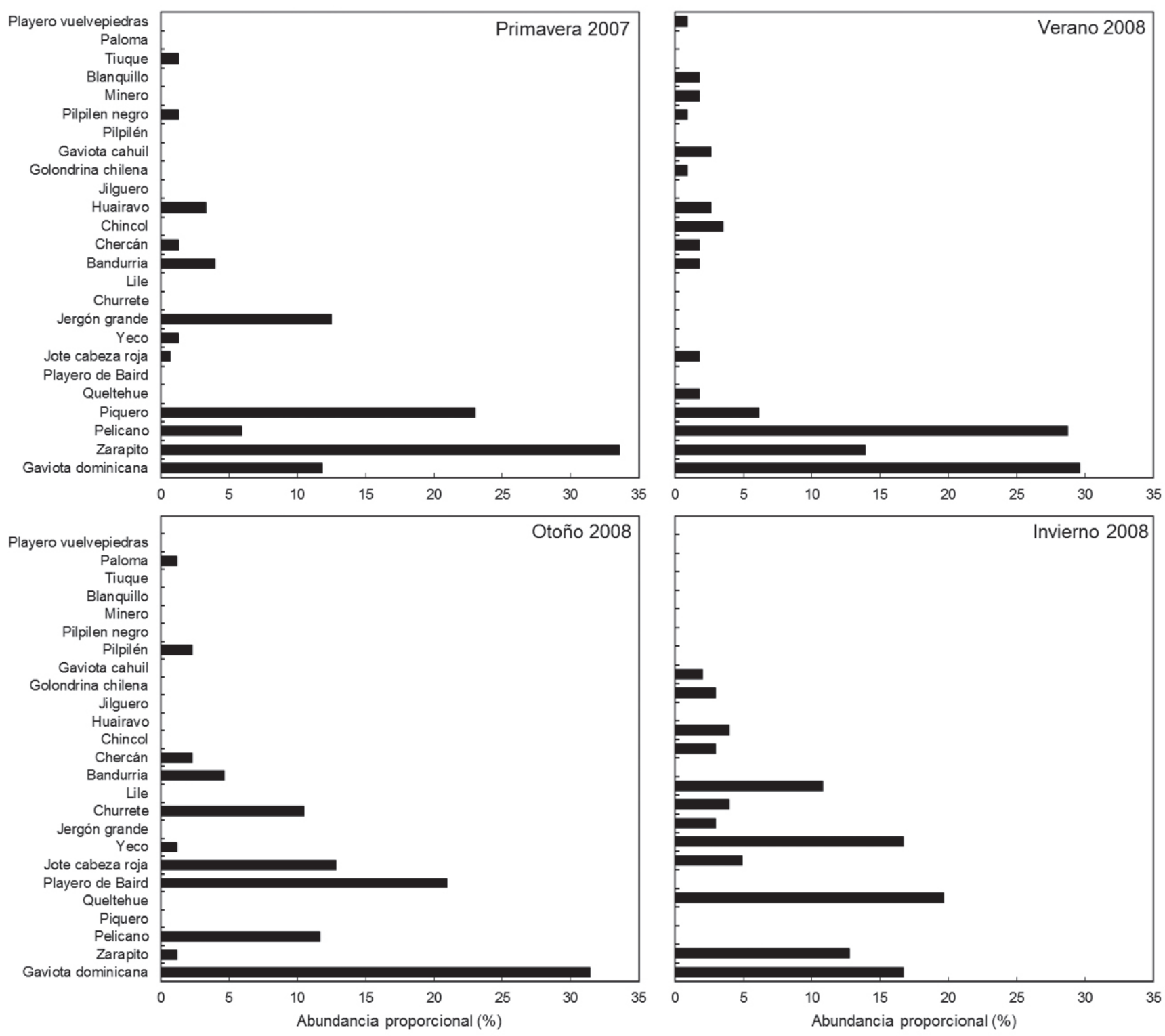

FiguRa 7. Variación estacional en la composición, riqueza y abundancia proporcional de aves en el borde costero de la Reserva Nacional Isla Mocha, sur de Chile. / Seasonal variation in composition, richness and relative abundance of birds in the coastline of Isla Mocha National Reserve, southern Chile. 

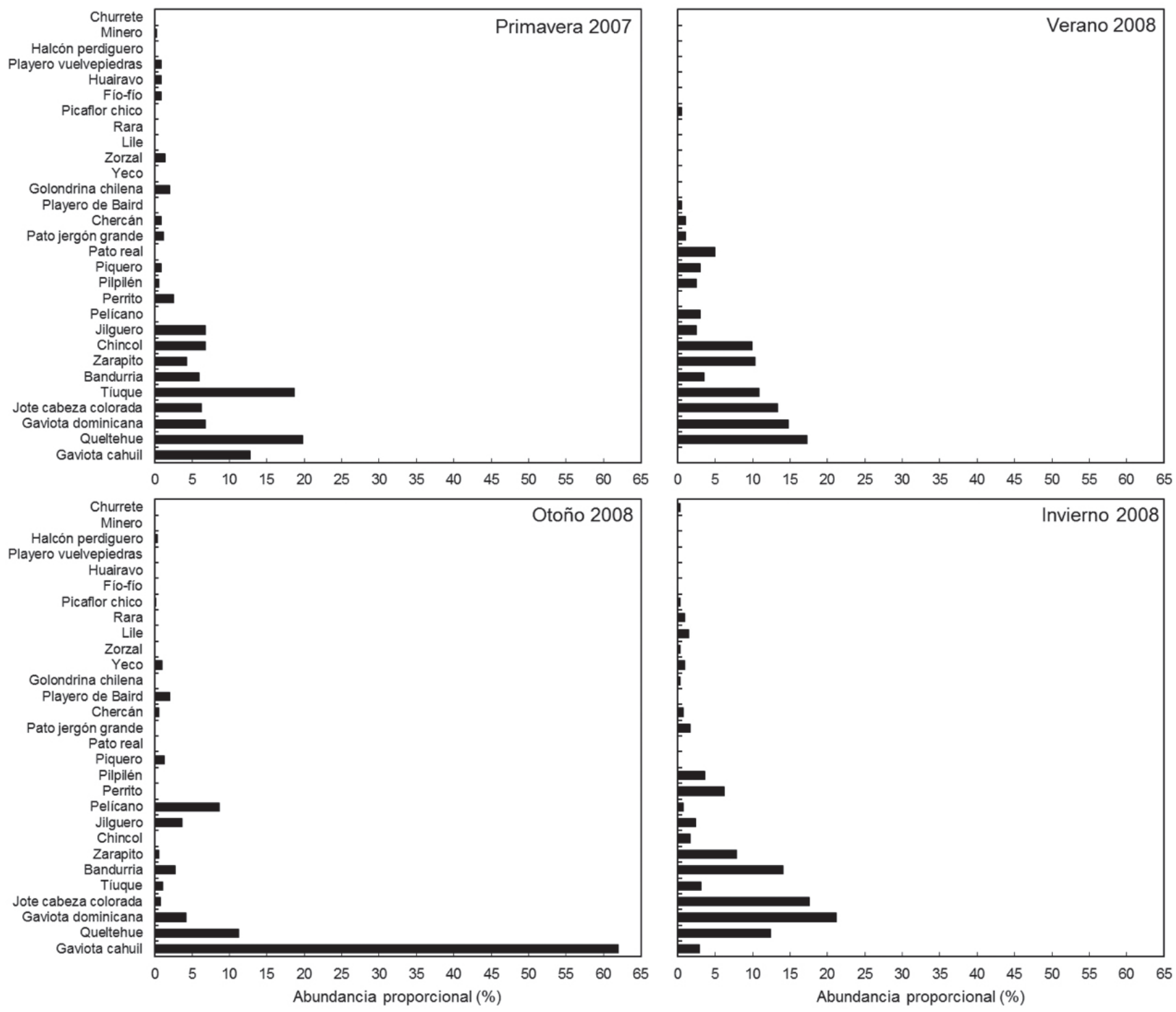

Figura 8. Variación estacional en la composición, riqueza y abundancia proporcional de aves en el pastizal de la Reserva Nacional Isla Mocha, sur de Chile. / Seasonal variation in composition, richness and relative abundance of birds in the pastureland of Isla Mocha National Reserve, southern Chile. 

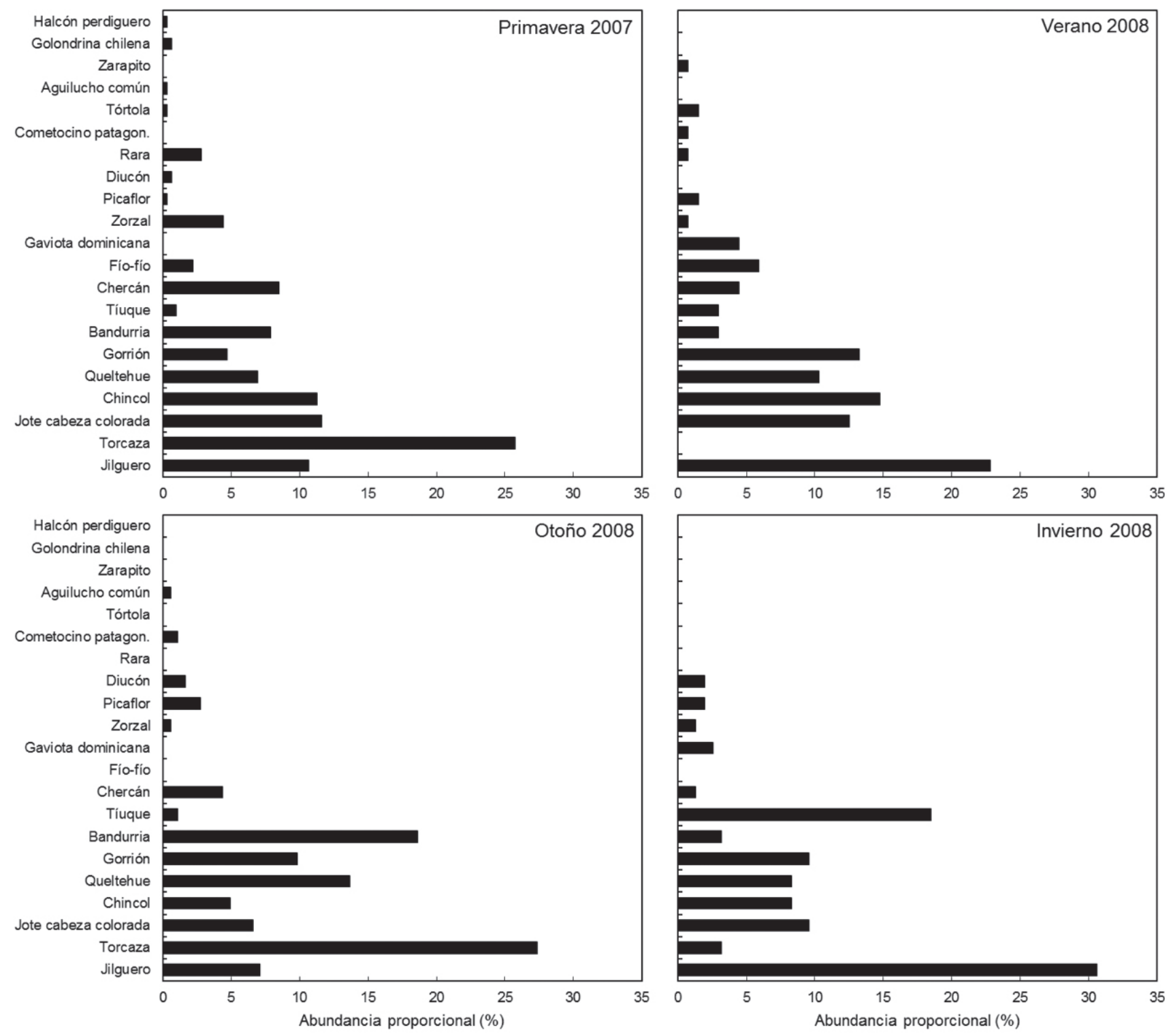

FIGURA 9. Variación estacional en la composición, riqueza y abundancia proporcional de aves en la pradera arbolada de la Reserva Nacional Isla Mocha, sur de Chile. / Seasonal variation in composition, richness and relative abundance of birds in the prairie with trees of Isla Mocha National Reserve, southern Chile. 

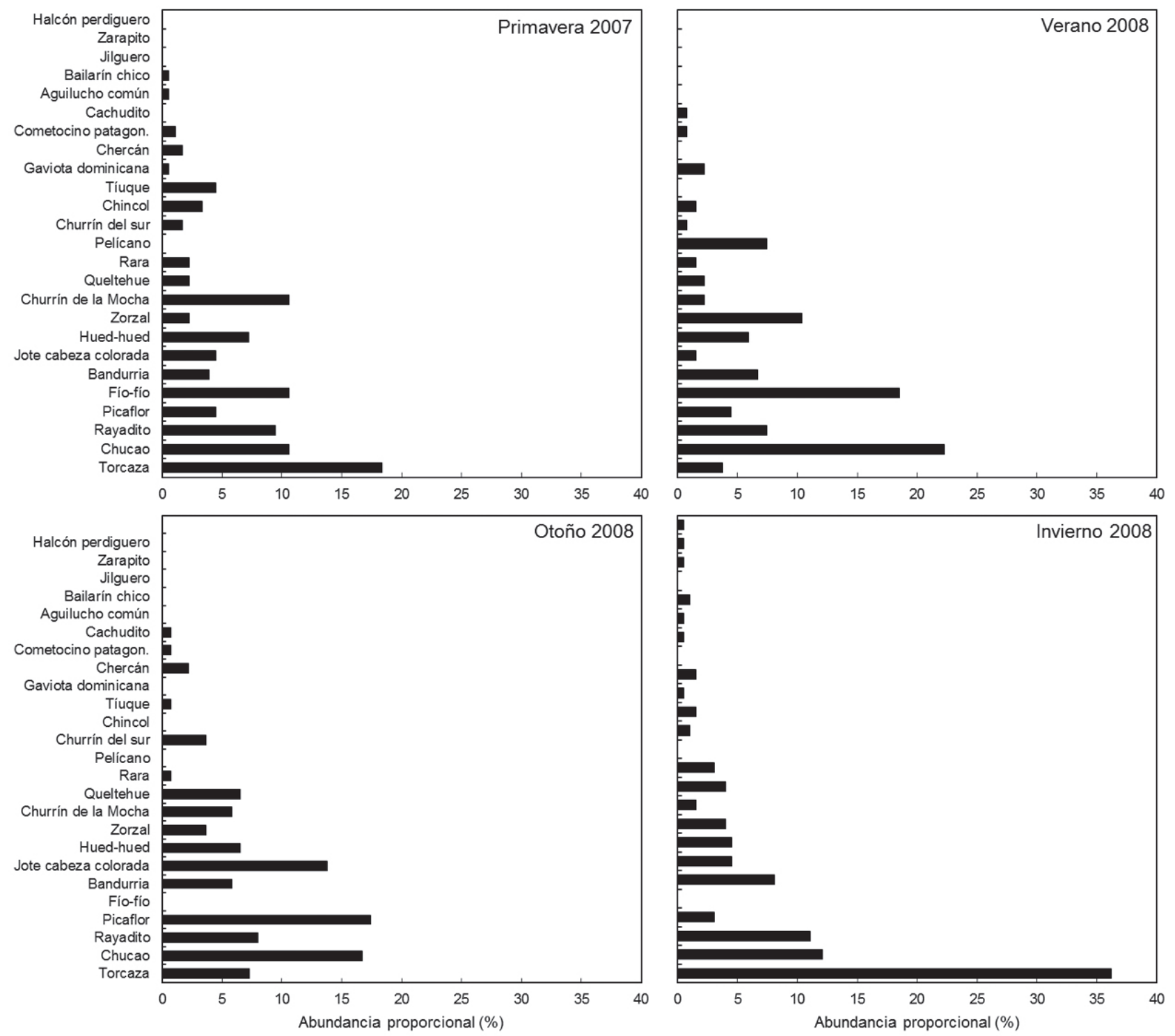

FIGURA 10. Variación estacional en la composición, riqueza y abundancia proporcional de aves en el ecotono bosque-pradera de la Reserva Nacional Isla Mocha, sur de Chile. / Seasonal variation in composition, richness and relative abundance of birds in the forest-grassland ecotone in Isla Mocha National Reserve, southern Chile.

En el ecotono bosque-pradera, la torcaza y el chucao (Scelorchilus rubecula) intercambiaron su dominancia numérica entre las estaciones climáticas (Fig. 10). No obstante, el fío-fío (Elaenia albiceps) y el picaflor chico (Sephanoides sephaniodes) estuvieron entre las especies más abundantes durante el verano y el otoño, respectivamente.
En el bosque valdiviano, el chucao, el rayadito (Aphrastura spinicauda), el picaflor chico y la torcaza tendieron a ser las especies más abundantes dentro de la comunidad de aves durante todas las estaciones climáticas (Fig. 11). Sin embargo, el chucao y el picaflor chico mostraron una mayor dominancia numérica durante el otoño. 

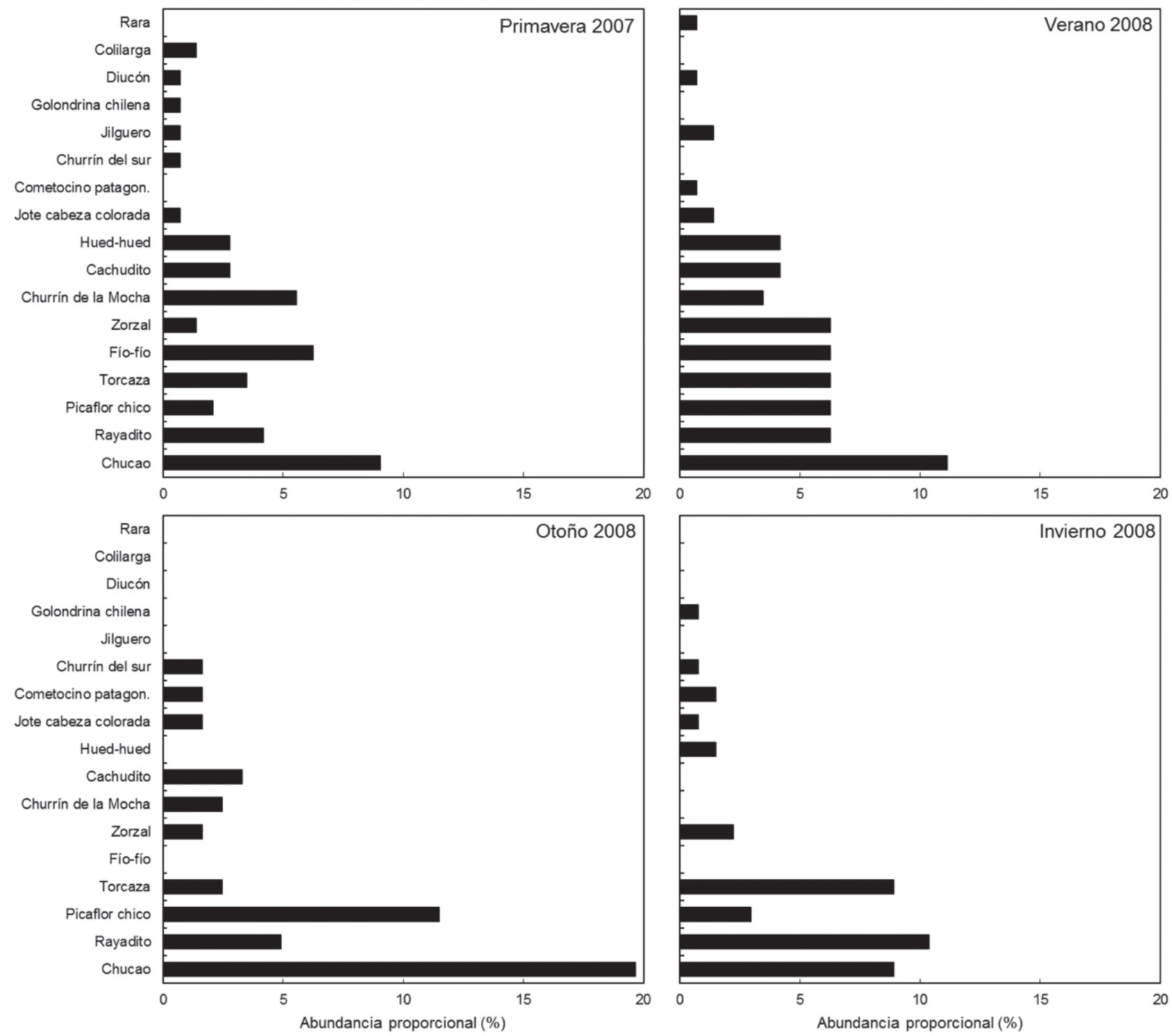

FiguRA 11. Variación estacional en la composición, riqueza y abundancia proporcional de aves en el bosque valdiviano de la Reserva Nacional Isla Mocha, sur de Chile. / Seasonal variation in composition, richness and relative abundance of birds in the Valdivian forest of Isla Mocha National Reserve, southern Chile. 
FLUCTUACIÓN NUMÉRICA ESTACIONAL

En todos los hábitats, las seis especies más frecuentes mostraron fluctuaciones numéricas estacionales. En el borde costero, la gaviota dominicana y el pelícano (Pelecanus thagus) exhibieron un aumento numérico importante durante el verano, declinando hacia el invierno (Fig. 12). El zarapito y el piquero exhibieron un aumento numérico considerable durante la primavera, declinando fuertemente hacia el otoño. El queltehue tuvo un alza numérica importante durante el invierno y el jote de cabeza colorada incrementó levemente su número hacia el otoño (Fig. 12).
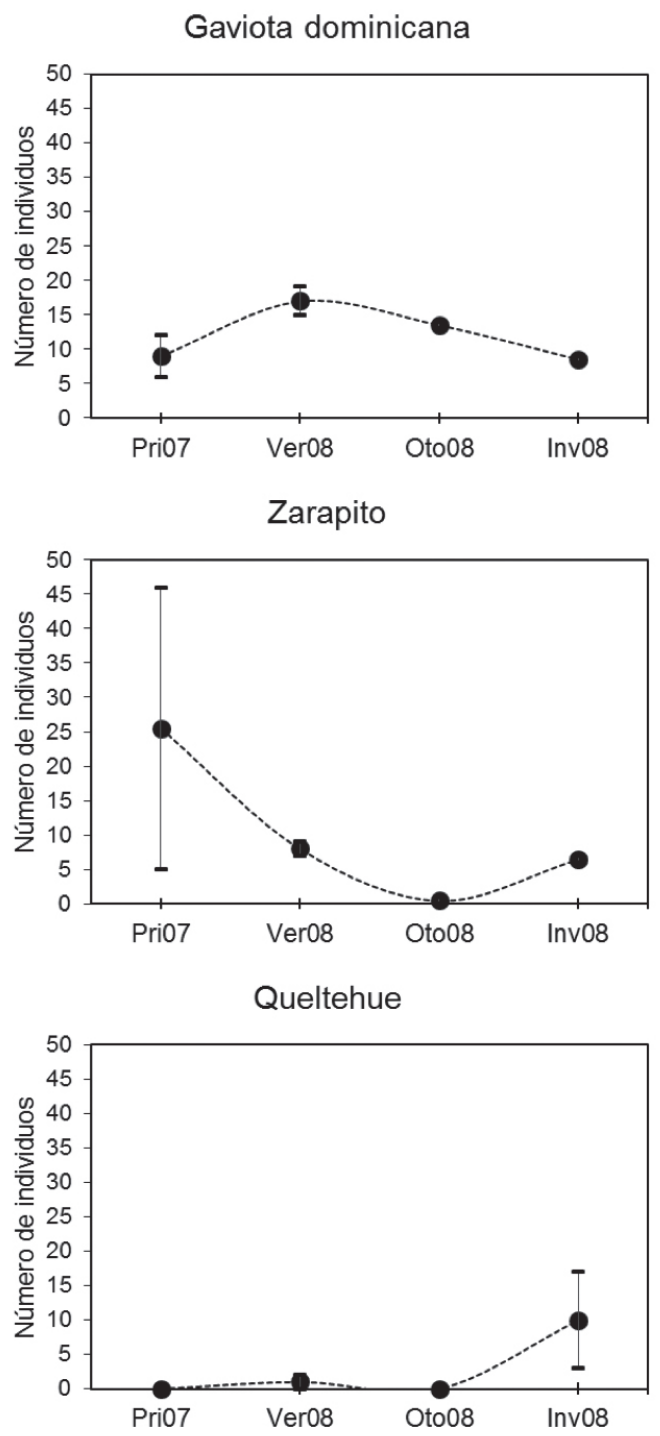

En el pastizal, la gaviota cahuil tuvo un fuerte incremento numérico durante el otoño, declinando hacia el invierno (Fig. 13). La gaviota dominicana, el jote de cabeza colorada, y la bandurria incrementaron en número hacia el invierno. El queltehue y el tiuque tendieron a ser más numerosos durante la primavera (Fig. 13). En la pradera arbolada, la torcaza, el jote cabeza colorada y el chincol (Zonotrichia capensis) fueron más numerosos en la primavera. La primera especie destacó por la gran cantidad de individuos observados en uno de los puntos de conteo durante esa estación (Fig. 14). El jilguero tendió a ser más numeroso hacia el invierno. El queltehue y la bandurria fueron más numerosos durante la primavera y el otoño (Fig. 14).
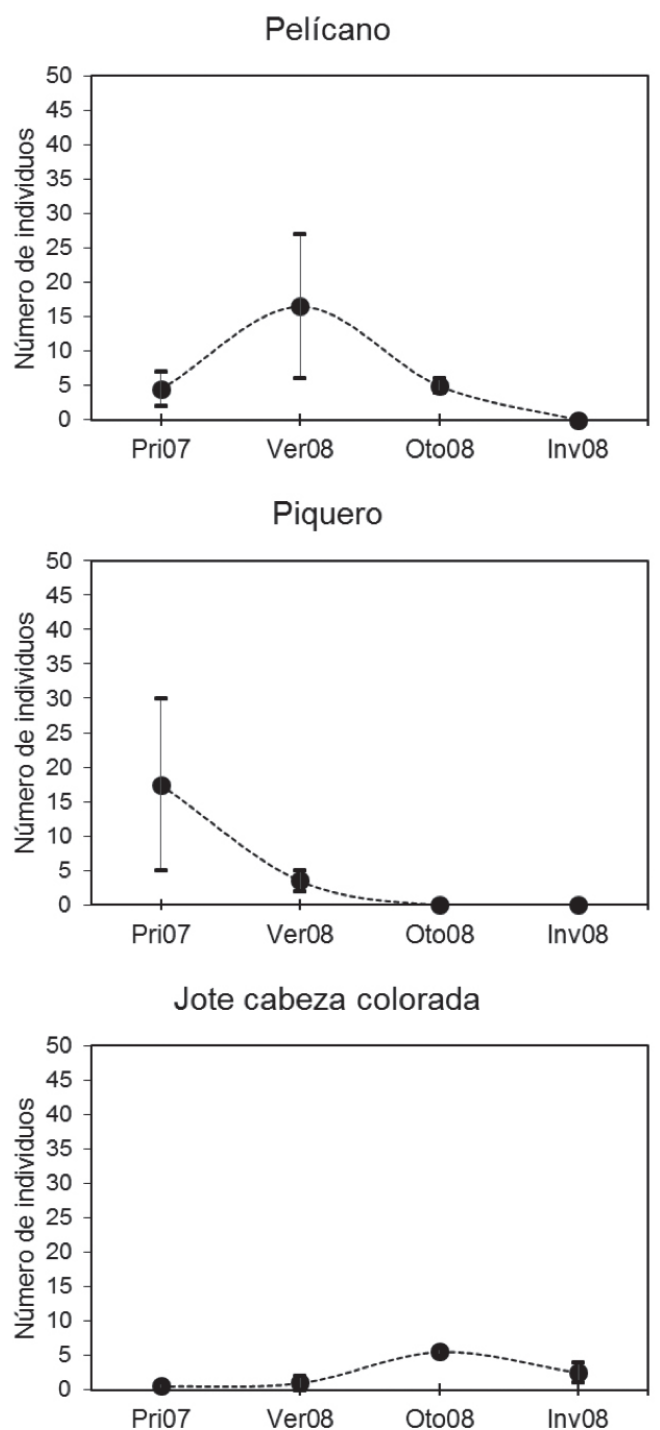

FIGURA 12. Fluctuación numérica estacional de las seis especies de aves más frecuentes en el borde costero de la Reserva Nacional Isla Mocha, sur de Chile. Los valores promedio fueron calculados sobre la base del número total de individuos registrados en dos puntos de conteo. Los puntos negros representan el número medio de individuos y las líneas verticales su amplitud (número máximo y mínimo). / Numerical seasonal fluctuation of the six most frequent bird species in the coastline of Isla Mocha National Reserve, southern Chile. Mean values were calculated from total number of individuals observed in two counting points. Dark spots represent mean number of individuals and vertical lines correspond to their range (maximum and minimum number). 


\section{Gaviota cahuil}

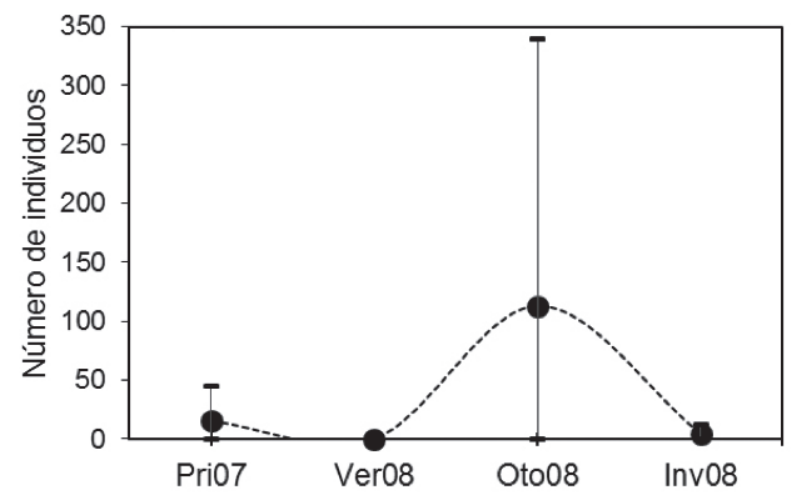

Gaviota dominicana

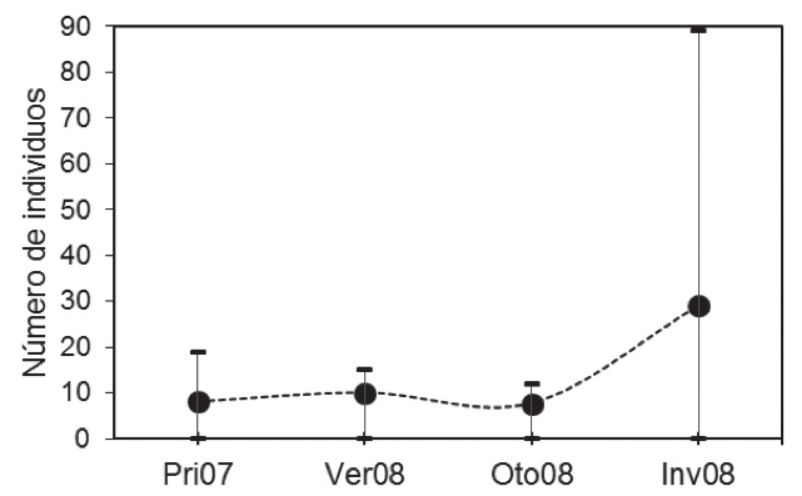

Bandurria

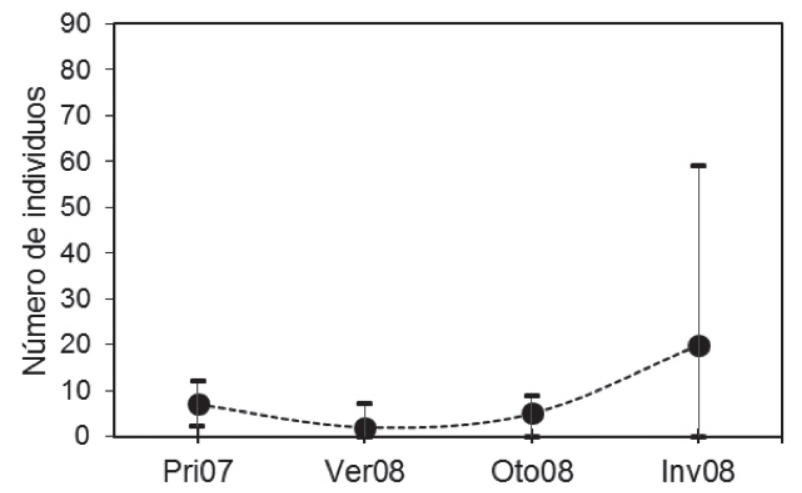

Queltehue

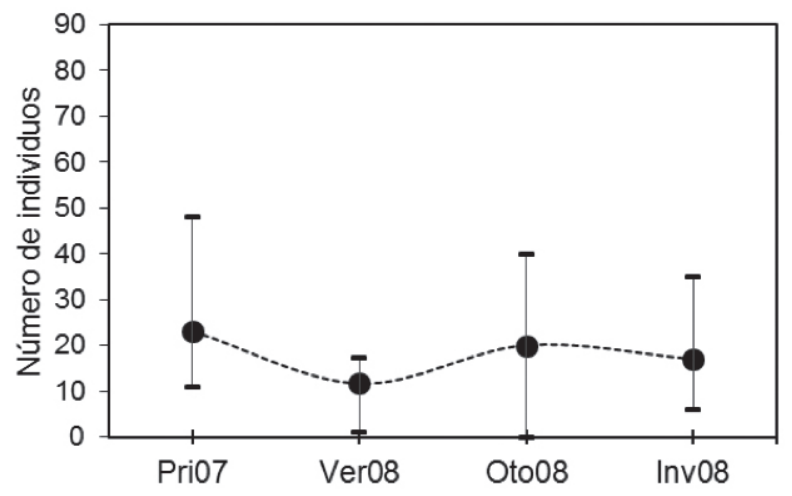

Jote cabeza colorada

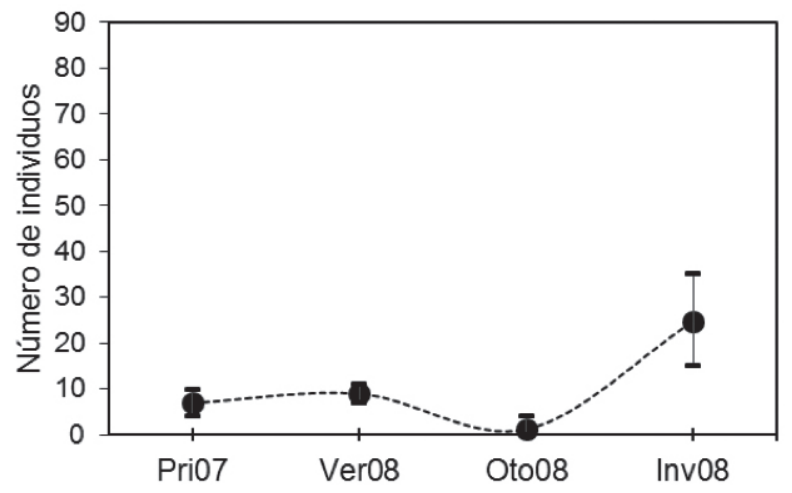

Tíuque

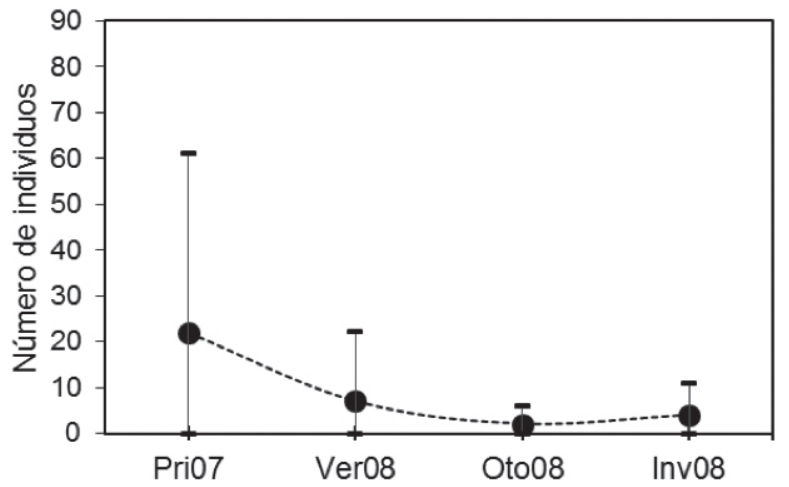

FIGURA 13. Fluctuación numérica estacional de las seis especies de aves más frecuentes en el pastizal de la Reserva Nacional Isla Mocha, sur de Chile. Los valores promedio fueron calculados sobre la base del número total de individuos registrados en tres puntos de conteo. Los puntos negros representan el número medio de individuos y las líneas verticales su amplitud (número máximo y mínimo). / Numerical seasonal fluctuation of the six most frequent bird species in the pastureland in Isla Mocha National Reserve, southern Chile. Mean values were calculated from total number of individuals observed in two counting points. Dark spots represent mean number of individuals and vertical lines correspond to their range (maximum and minimum number). 
Torcaza

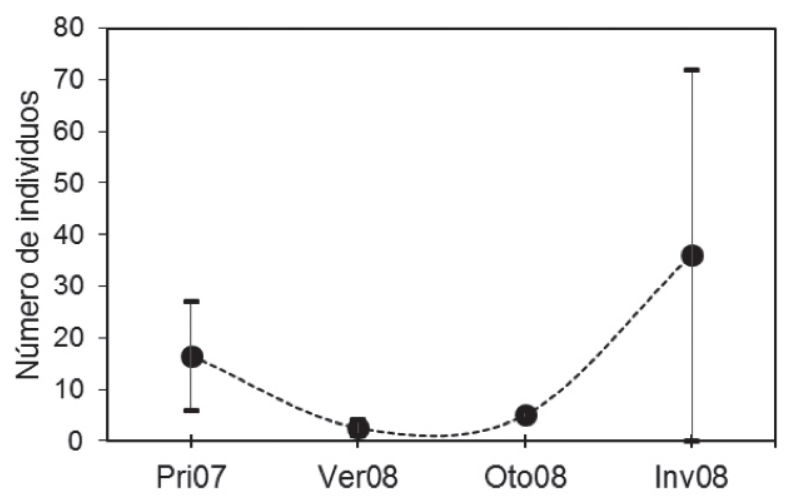

Rayadito

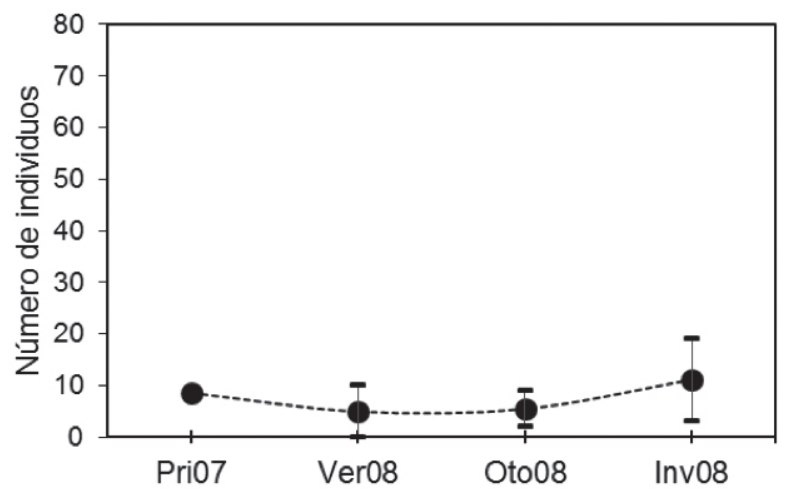

Fío-fío

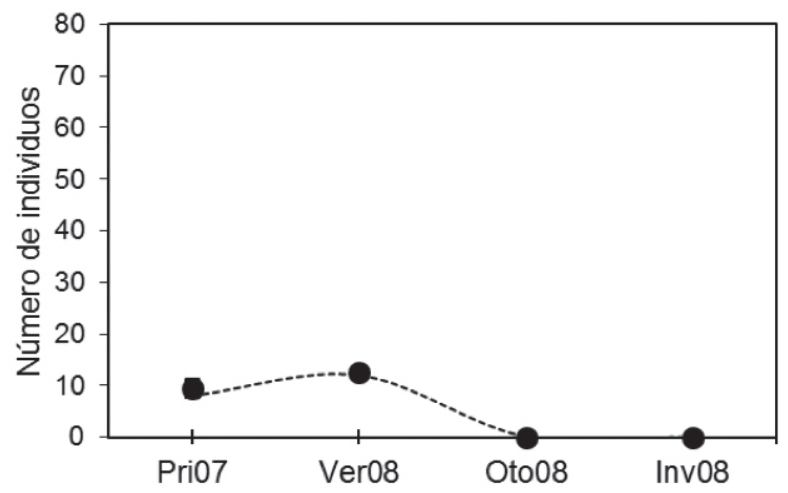

\section{Chucao}

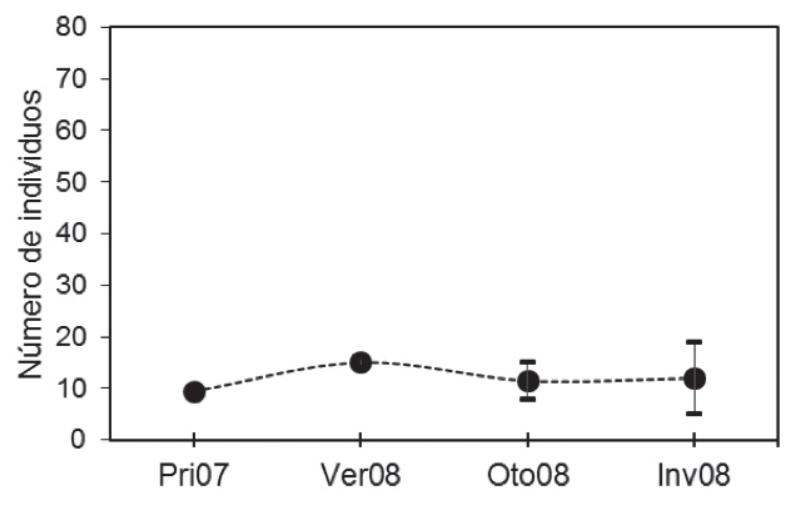

Picaflor chico

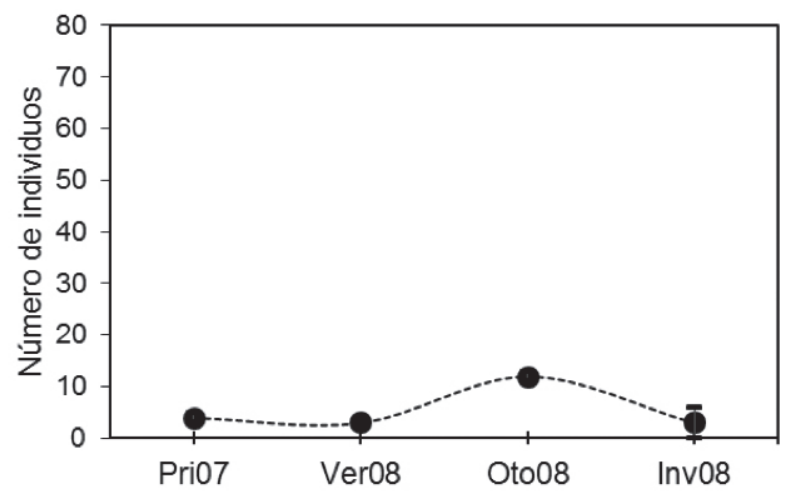

Bandurria

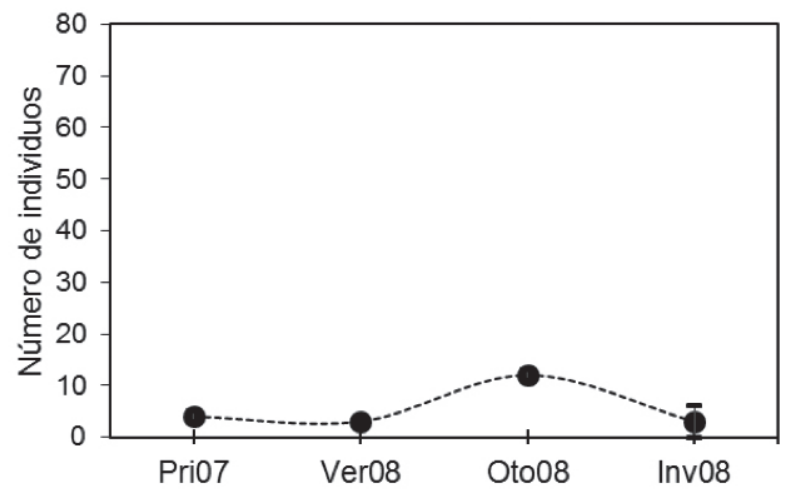

FIGURA 14. Fluctuación numérica estacional de las seis especies de aves más frecuentes en la pradera arbolada de la Reserva Nacional Isla Mocha, sur de Chile. Los valores promedio fueron calculados sobre la base del número total de individuos registrados en dos puntos de conteo. Los puntos negros representan el número medio de individuos y las líneas verticales su amplitud (número máximo y mínimo). / Numerical seasonal fluctuation of the six most frequent bird species in the prairie with trees in Isla Mocha National Reserve, southern Chile. Mean values were calculated from total number of individuals observed in two counting points. Dark spots represent mean number of individuals and vertical lines correspond to their range (maximum and minimum number). 
En el ecotono bosque-pradera, la única especie que tuvo una fluctuación numérica considerable fue la torcaza. Esta especie alcanzó un máximo de casi 30 individuos en primavera, 4-6 individuos en otoño-invierno y casi 70 individuos en invierno (Fig. 15). Exceptuando al fío-fío que está ausente durante el otoño y el invierno, las especies restantes tuvieron fluctuaciones numéricas estacionales leves a lo largo del año. El picaflor chico y la bandurria incrementaron hacia el otoño, y el chucao tuvo fluctuaciones poco notorias (Fig. 15).
En el bosque valdiviano, las seis especies más frecuentes mostraron fluctuaciones numéricas marcadas. El chucao y el picaflor chico mostraron un patrón similar en su fluctuación, incrementando consistentemente desde la primavera hacia el otoño y declinando notoriamente hacia el invierno (Fig. 16). El rayadito y la torcaza también mostraron un patrón similar respecto de su variación numérica. Estas especies incrementaron su número desde la primavera hacia el verano, disminuyendo numéricamente hacia el otoño, y
Torcaza
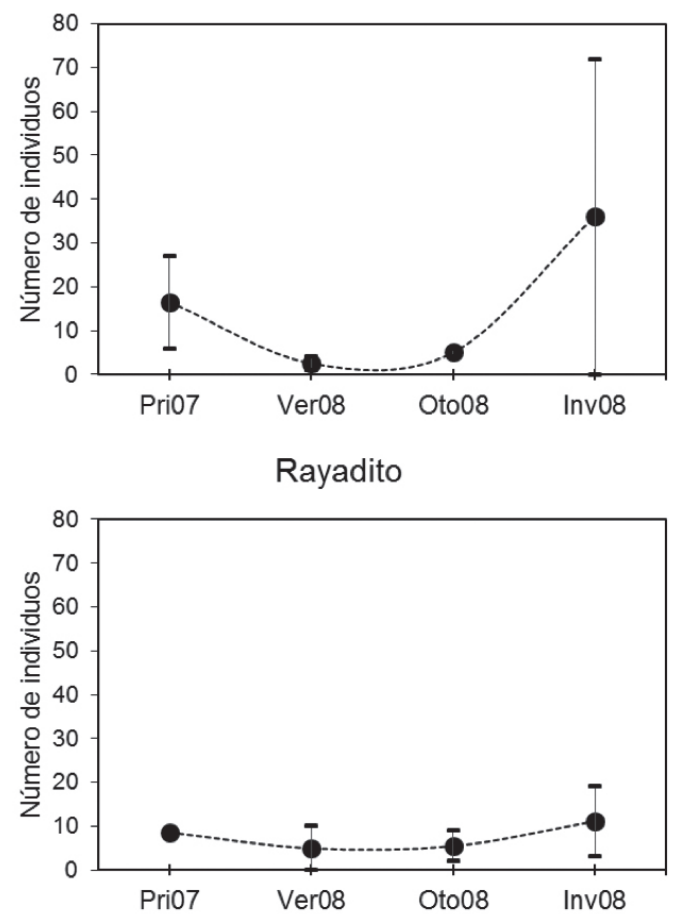

Fío-fío

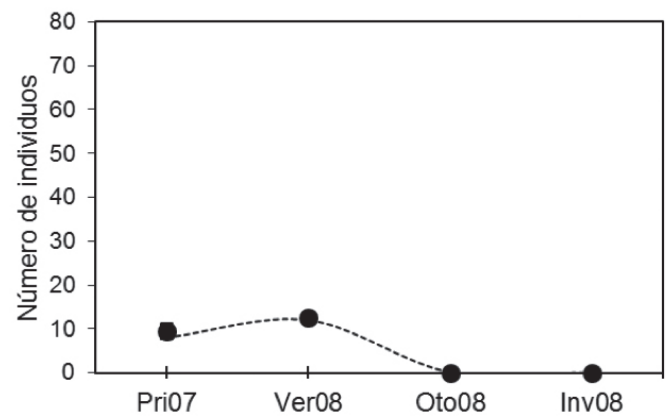

Chucao
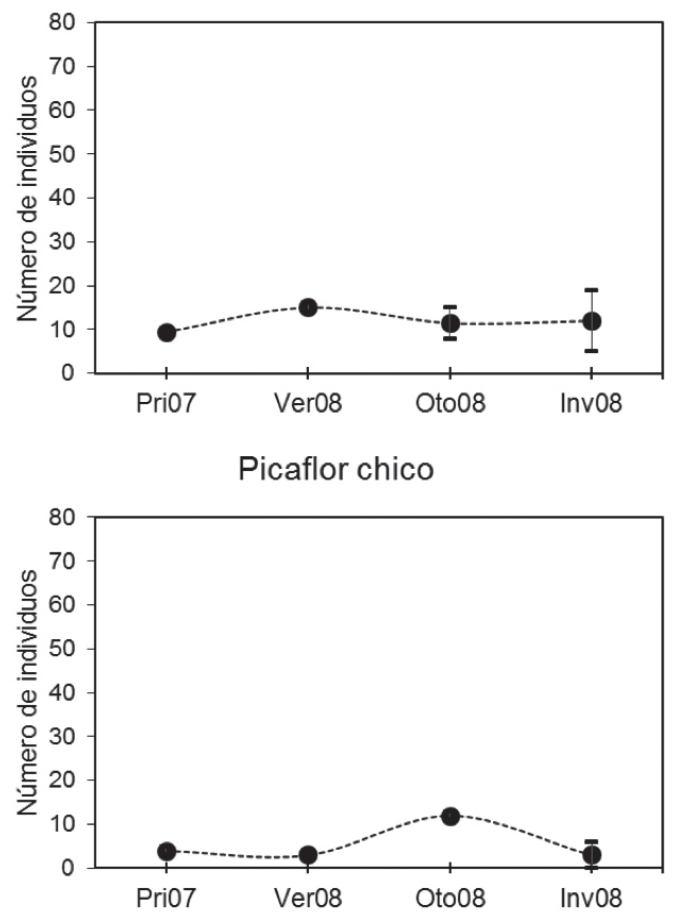

Bandurria

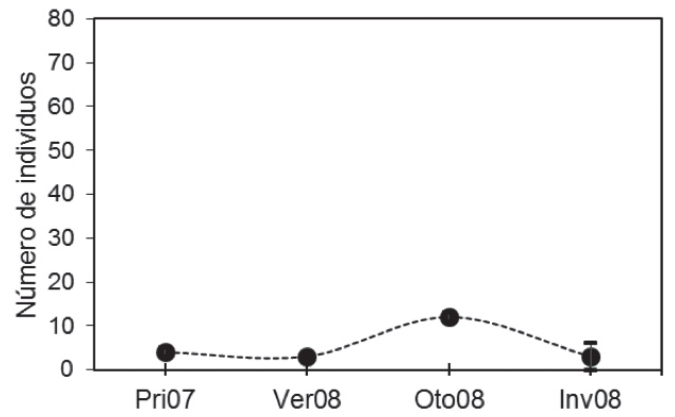

FiguRA 15. Fluctuación numérica estacional de las seis especies de aves más frecuentes en el ecotono bosque-pradera de la Reserva Nacional Isla Mocha, sur de Chile. Los valores promedio fueron calculados sobre la base del número total de individuos registrados en dos puntos de conteo. Los puntos negros representan el número medio de individuos y las líneas verticales su amplitud (número máximo y mínimo). / Numerical seasonal fluctuation of the six most frequent bird species in the forest-grassland ecotone in Isla Mocha National Reserve, southern Chile. Mean values were calculated from total number of individuals observed in two counting points. Dark spots represent mean number of individuals and vertical lines correspond to their range (maximum and minimum number). 
aumentando marcadamente su número hacia el invierno (Fig. 16). Al igual que en el ecotono bosque-pradera, el fíofío mantuvo su tamaño numérico durante la primavera y el verano. El churrín de la Mocha (Eugralla paradoxa) tuvo un consistente decline numérico desde la primavera hacia el invierno (Fig. 16).
DiVERSIDAD PROPORCIONAL DE ESPECIES

El hábitat más diverso en especies de aves fue el ecotono bosque-pradera $\left(\mathrm{C}_{i n v}=10,9\right)$, seguido de la pradera arbolada $\left(\mathrm{C}_{i n v}=9,6\right)$, el borde costero $\left(\mathrm{C}_{i n v}=9\right)$, el pastizal $\left(\mathrm{C}_{i n v}=8,1\right)$ y el bosque valdiviano $\left(\mathrm{C}_{i n v}=7,9\right)$. Nótese que las diferencias de diversidad entre los hábitats no son considerables, ya que en todos ellos hubo un número similar de especies que se distribuyeron casi equitativamente respecto de su abundancia.
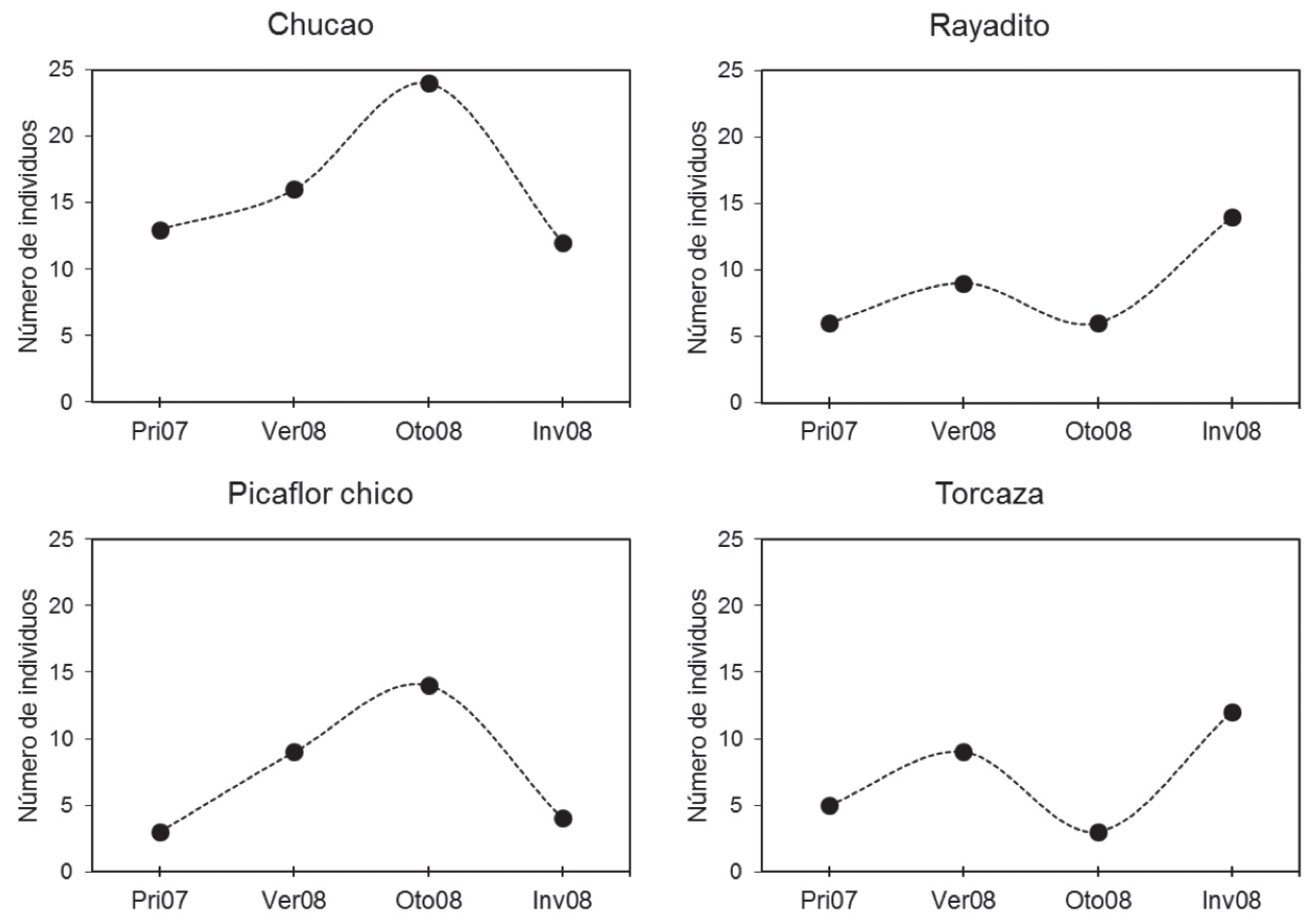

Fío-fío
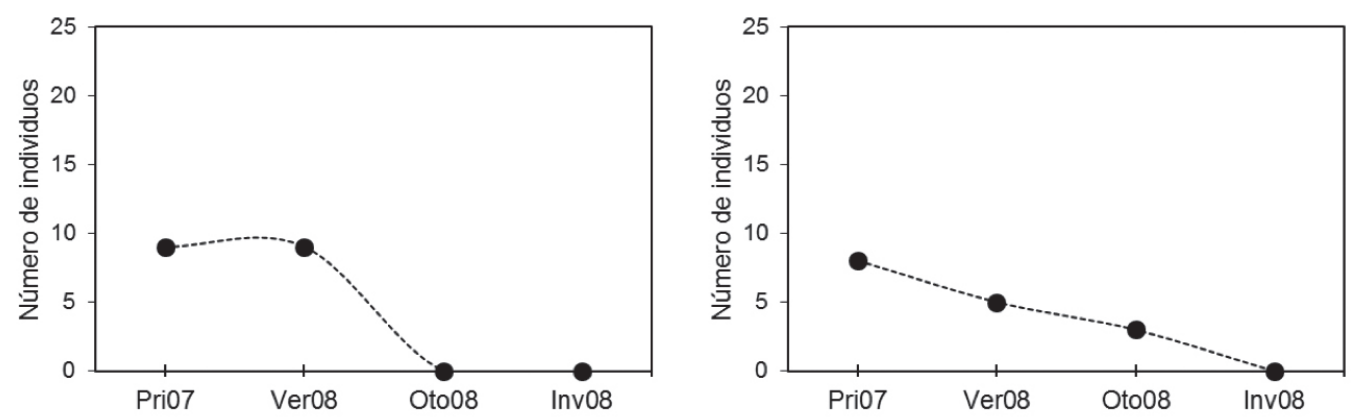

Figura 16. Fluctuación numérica estacional de las seis especies de aves más frecuentes en el bosque valdiviano de la Reserva Nacional Isla Mocha, sur de Chile. Los puntos negros representan el número absoluto de individuos registrado en un único punto de conteo. / Numerical seasonal fluctuation of the six most frequent bird species in the Valdivian forest of Isla Mocha National Reserve, southern Chile. Dark spots represent absolute number of individuals observed in a unique counting point. 


\section{DISCUSIÓN}

La cantidad total de especies de aves observadas durante nuestro estudio representa casi el $75 \%$ de las especies registradas históricamente en la Reserva Nacional Isla Mocha (ver Apendice 1). A la vez, la riqueza de especies registradas por nosotros es similar a la documentada por Cañas (1902: 68 especies) y Housse (1924, 1925: 75 especies). Sin embargo, es menor que la riqueza estimada por Bullock (1935: 92 especies) y Péfaur \& Humphrey (1995: 99 especies). Estas discordancias son explicables por las diferencias en los métodos y esfuerzo de muestreo, y los criterios usados por los distintos autores. Por ejemplo, Péfaur \& Humphrey (1995) incluyeron especies pelágicas y accidentales. Cabe recordar que en nuestro estudio un tercio de todas las especies registradas fueron observadas fuera de los puntos de conteo, incluyendo a la fardela blanca, cuya población estaría en riesgo de disminución. Esto indica que la cantidad de réplicas fue insuficiente para registrar a todas las especies de la isla sólo dentro de los puntos de conteo. Además, la diferencia en los horarios de conteo pudo sesgar la detectabilidad de ciertas especies debido a diferencias en la actividad circadiana. Por otra parte, esto confirma que los registros ocasionales son un buen complemento de los métodos sistemáticos para el determinar la riqueza local de especies de aves (López-Calleja 1989, Anderson \& Rozzi 2001).

Considerando todos los estudios de aves realizados hasta la fecha, la proporción de especies terrestres y acuática en el área de estudio es bastante equitativa (53,2\% vs 46,8\% del total de especies; Apendice 1). Esta es una característica típicas de islas oceánicas cercanas al continente (Reyes-Arriagada et al. 2009). Asimismo, hubo bastante equitatividad entre aves acuáticas dulce-acuícolas, acuáticas marinas, terrestres de hábitats abiertos y terrestres de hábitats boscosos (ver Apendice 1). Esto es un indicador de la alta y equitativa diversidad de hábitats presentes en la Reserva Nacional Isla Mocha.

Todos los hábitats tuvieron una comunidad propia de aves con distinta composición y riqueza de especies. En general, la composición de aves en cada tipo de hábitat de la isla mostró cierta similitud a la observada en hábitats continentales similares. Muchas de las especies del borde costero, del pastizal y de la pradera arbolada de la isla han sido registradas también en las áreas costeras, pastizales y praderas agrícolas continentales del sur de Chile (Figueroa \& Quintana 2001, Figueroa \& Corales 2004, GonzálezAcuña et al. 2006, Cursach \& Rau 2008, Silva-Rodríguez et al. 2008, Cursach et al. 2011). Casi todas las especies observadas en el ecotono bosque-pradera y el bosque valdiviano de la isla Mocha también forman parte de la comunidad típica de aves del bosque valdiviano continental (Jaksic \& Feinsinger 1991, Gantz \& Rau 1999, SilvaRodríguez et al. 2008) y de otras islas cercanas a la costa del sur de Chile (Willson et al. 1994, Rozzi et al. 1996, Jiménez 2000). En su conjunto, la composición y riqueza de aves de la isla Mocha también es similar a la existente en otras islas australes cercanas a la costa continental (Reyes-Arriagada et al. 2009).

Independiente de lo anterior, la riqueza total de especies en cada hábitat fue influenciada por la contribución de especies provenientes de los hábitats circundantes. En algunos casos, esta contribución fue mínima y en otros fue considerable. En el borde costero, registramos cuatro especies típicas de praderas (jilguero, chincol, queltehue, bandurria) y una comensal (paloma). En el pastizal registramos 10 especies típicas del borde costero (ver Fig. 3). En la pradera arbolada registramos varias especies típicas del bosque valdiviano (e.g., torcaza, fío-fío, zorzal, picaflor chico). Exceptuando el jote de cabeza colorada, todas las especies presentes en el bosque valdiviano fueron típicas de este tipo de hábitat.

La presencia de una especie en un hábitat "no típico" se debió ya sea a la disponibilidad permanente o temporal de microhábitats atrayentes, la capacidad de desplazamientos, y la inmediata cercanía a otro tipo de hábitat. En el borde costero, pequeños parches de pastizales y matorrales pudieron atraer a chincoles y jilgueros. En primavera, las lagunillas formadas después de las lluvias en el borde costero atrajeron al jergón grande (Anas georgica), al queltehue y a la bandurria. La presencia de árboles con frutos o cultivos agrícolas pudo atraer a la torcaza hacia las praderas arboladas. La capacidad de desplazamiento de la gaviota dominicana, la bandurria, del queltehue, jote de cabeza colorada y del tiuque explicarían su presencia en casi todos los tipos de hábitat de la isla Mocha. En el caso particular del pastizal, la presencia de un número importante de aves marinas se debe a su estrecha cercanía con el borde costero. De hecho, varias especies típicas del borde costero, tales como gaviotas y playeros, visitaron los pastizales para alimentarse o descansar.

La distribución de la abundancia de aves en cada tipo hábitat de la isla Mocha mostró un patrón típico de distribución de abundancia de varios tipos de organismos (Preston 1948, Jaksic 2001): pocas especies fueron muy abundantes o poco abundantes, y varias fueron medianamente abundante. Además, muchas especies mostraron patrones de abundancia similares a los observados en áreas continentales. La gaviota dominicana y el queltehue, dos de las especies más abundantes en el borde costero de la isla Mocha, son también dos de las más abundantes en áreas costeras del sur de Chile (Cursach \& Rau 2008, Cursach et al. 2011). La gaviota cahuil, la especie más abundante en el pastizal, suele ser una especie muy numerosa en pastizales manejados y praderas de cultivo del sur de Chile (R.A. Figueroa, obs. pers.). Otras especies abundantes en el pastizal de la isla, tales como el jilguero, chincol, queltehue y bandurria, tienden a ser también comunes en los pastizales continentales (Figueroa \& Corales 2004, González-Acuña 
et al. 2006, Silva-Rodríguez et al. 2008). Varias especies presente en la pradera arbolada de la isla muestran patrones de abundancia similares a los observados en praderas agrícolas arboladas en el sur de Chile continental. Estas incluyen a la torcaza, el jilguero, el chincol, el queltehue, la bandurria y el jote de cabeza colorada (ver Estades 1994, Figueroa \& Quintana 2001, Figueroa \& Corales 2004, González-Acuña et al. 2006, Silva-Rodríguez et al. 2008). A propósito, nótese que el chirihue, una de las especies numéricamente predominante en praderas arboladas continentales (Estades 1994, Figueroa \& Corales 2004, González-Acuña et al. 2006, Silva-Rodríguez et al. 2008) está ausente en la isla Mocha. Las abundancias relativas de varias especies de aves registradas en el ecotono bosque-pradera y el bosque valdiviano coinciden en gran parte con lo observado en remanentes continentales de bosque valdiviano (ver Erazo 1984, Willson et al. 1994, Rozzi et al. 1996, Gantz \& Rau 1999). En este último caso, corroboramos la existencia de un conjunto de especies de aves que son elementos regulares a lo largo de la distribución del bosque valdiviano (Willson et al. 1994).

En todos los hábitats ocurrieron cambios temporales en la distribución de las abundancias específicas. Esto fue más notorio en aquellas especies más frecuentes o regulares dentro de cada hábitat. Aun cuando desconocemos las causas reales de estos cambios temporales, es posible que hayan sido generados por factores ambientales, ecológicos o conductuales, o una combinación de éstos. En el caso de la gaviota dominicana, la mayor cantidad de individuos registrados en el borde costero durante el verano se debió a que estas comenzaron a agruparse para iniciar su reproducción colonial. No obstante, en el pastizal esta especie tuvo un fuerte incremento numérico durante el invierno. Durante esa estación, las gaviotas dominicanas se concentraron alrededor de lagunillas temporales formadas por la lluvia, las cuales podrían haber constituido una fuente alternativa de alimento.

El fuerte incremento numérico de la gaviota cahuil durante el otoño en el pastizal fue el resultado de la presencia de grandes bandadas (89-250 individuos) atraídas, al parecer, por lagunillas ricas en presas invertebradas. La gaviota cahuil tiende a alimentarse principalmente de larvas de insectos presentes en charcos, lagunillas y suelos blandos (Lizurume et al. 1995, Jackson 2008). Por otra parte, algunos autores afirman que la gaviota cahuil se congrega comúnmente en áreas costeras antes de migrar hacia el norte en invierno (Martínez \& González 2005). Sin embargo, desconocemos si la población de la isla Mocha es parte de este proceso migratorio. Su fuerte caída numérica durante primavera y verano en el pastizal pudo deberse a que durante este periodo la especie restringe su actividad a sus sitio reproductivos (Lizurume et al. 1995).

Es evidente que la gaviota dominicana y gaviota cahuil constituyen elementos predominantes en la comunidad de aves de la Isla Mocha. Esto no es sorprendente ya que ambas especies son comunes y numerosas en otras áreas costeras insulares y continentales. Este predominio numérico es explicable porque tanto la gaviota dominicana como la gaviota cahuil son especies tróficamente oportunistas con una gran capacidad de adaptación a la modificación del paisaje (Belant 1997). Las dos especies consumen un amplio espectro de recursos tróficos incluyendo presas vivas, carroña y desechos de animales procesados (Bahamondes \& Castilla 1986, Lizurume et al. 1995, Petracci et al. 2004, Giaccardi et al. 1997, Bertellotti \& Yorio 1999, Silva et al. 2000). Incluso, la gaviota cahuil se congrega en bandadas numerosas en áreas agrícolas para sacar provecho de la oferta aumentada de larvas de insectos y lombrices que quedan expuestas durante las faenas de barbecho (R. A. Figueroa, obs. pers.).

En el pastizal y la pradera arbolada, el queltehue tendió a ser numéricamente estable a lo largo del año, excepto por un muy leve incremento durante primavera y otoño. Esta estabilidad se explicaría por la residencialidad de las parejas reproductivas (Goodall et al. 1951), y los leves incrementos numéricos serían un balance entre el reclutamiento de juveniles y su mortalidad por depredadores (González-Acuña et al. 2006). No obstante, nótese que en el borde costero el queltehue tuvo un aumento numérico importante en invierno. Esto pudo deberse a que los individuos o parejas que residen en el pastizal o la pradera arbolada se desplazaron durante esa época hacia las playas respondiendo posiblemente a una oferta aumentada de presas invertebradas. Las distintas tendencias estacionales del jote de cabeza colorada en los distintos tipos de hábitats son explicable por sus desplazamientos extensos y conducta trófica oportunista.

En el borde costero, el zarapito y el piquero mostraron una tendencia numérica estacional muy similar. Sin embargo, en el primer caso se debe a que la especie es un visitante estival que migra desde el hemisferio norte congregándose en grupos numerosos a lo largo de la costa continental e islas del sur de Chile (Canevari et al. 2001, Martínez \& González 2005). En el caso del piquero y del pelícano, el mayor número de individuos observados en la época estival pudo deberse a una aumento temporal en la disponibilidad de alimento, a su conducta de cazar en bandadas y/o a la cercanía con alguna colonia de nidificación (Martínez \& González 2005, Hucke-Gaete \& Ruiz 2010). A casi 1 km al sur de la isla Mocha, existe un islote ("Islote del Muerto") donde hay colonias reproductivas de pelicanos, piqueros, liles y cormoranes de las rocas.

El incremento numérico de la bandurria durante el otoño tanto en la pradera arbolada como en el ecotono bosquepradera pudo deberse principalmente al reclutamiento de individuos juveniles. En tanto, el notorio aumento del número de individuos durante el invierno en el pastizal se explicaría por una mayor congregación de individuos para 
forrajear en ese hábitat. El marcado incremento numérico del jilguero hacia el invierno en la pradera arbolada pudo ser el resultado de la incorporación de individuos juveniles a la población y su conducta de formar bandadas numerosas, las cuales a menudo se refugian en arbustos frondosos.

El aumento numérico de la torcaza hacia el invierno en el bosque valdiviano y el ecotono bosque-pradera, y durante la primavera en la pradera arbolada se explicaría por varios factores. Como ocurre en áreas continentales, en la isla las torcazas forman grandes bandadas a partir del otoño. Después del verano, la especie tiene un fuerte incremento numérico como resultado del reclutamiento de individuos juveniles y la abundancia de frutos nativos (e.g. olivillo). Durante el invierno, las bandadas de torcaza en la isla se refugiaron y alimentaron en el borde e interior del bosque. Sin embargo, durante la primavera también buscaron semillas y frutos en áreas cultivadas cercanas. Aunque la torcaza es dependiente del bosque (Jaksic \& Feinsinger 1991, Rozzi et al. 1996), esta especie ha sacado provecho de la alta disponibilidad de grano en los campos cultivados. Su disminución numérica en la pradera arbolada y el ecotono bosque-pradera, y su incremento en el bosque valdiviano durante el verano se debió a que durante esa época las torcazas se restringieron a sus sitios reproductivos al interior del bosque. La torcaza fue descrita previamente como una de las especies de aves más abundantes en la Isla Mocha (Martínez \& González 2005). Bullock (1935) afirma que esta especie era fuertemente cazada por los lugareños, tiempo en el cual no había control sobre su captura. Así, la prohibición actual de caza estaría promoviendo su recuperación en la isla.

El fuerte incremento numérico del chucao y picaflor chico en el bosque valdiviano hacía el otoño se explicaría por el reclutamiento de individuos juveniles y un aumento de su actividad ante la disponibilidad de recursos tróficos. Durante el otoño muchas especies de plantas leñosas del bosque valdiviano ofrecen semillas para los chucaos y recursos florales para los picaflores (Correa et al. 1990, Smith-Ramírez 1993). No tenemos una explicación cierta del aumento numérico del rayadito durante el invierno, pero es posible que los individuos reclutas se hayan sumado tardíamente a la población. La tendencia numérica estacional del fío-fío claramente refleja su conducta migratoria. Al principio del otoño, esta especie abandona totalmente sus áreas reproductivas en el sur de Chile para pasar el invierno en áreas boscosas del norte de Sudamérica (Rozzi et al. 1996, Brown et al. 2007). El consistente decline en el registro del churrín de la Mocha hacia el invierno posiblemente se debió a una restricción de su actividad o mortalidad natural.

La mayor diversidad proporcional de especies en el ecotono bosque-pradera es explicable por la combinación de una alta riqueza de especies y una mayor equitatividad numérica de las especies más frecuentes. En general, los ecotonos tienden a ser mucho más ricos en especies dada la convergencia de dos hábitats estructural y funcionalmente distintos (López-Barrera 2004, Copatti et al. 2007). No obstante, los hábitats de ecotono no han sido estudiados en términos de diversidad de especies en Chile. La menor diversidad de especies en el bosque valdiviano fue una combinación entre un menor número de especies y el alto predominio numérico del chucao. Aunque el borde costero y el pastizal fueron ricos en especies, el predominio numérico de unas pocas especies hizo que estos sean menos diversos que la pradera arbolada.

Aun cuando muchos de los argumentos anteriores son ciertos o razonables, en algunos casos es posible que las tendencias observadas sean más bien un artefacto de las restricciones del diseño de muestreo. Para corregir esta potencial desventaja, futuros estudios deberán incrementar el número de puntos de muestreo en cada tipo de hábitat y estandarizar los horarios de los conteos.

Las Áreas Silvestres Protegidas (ASP), cumplen un rol importante en la conservación de la diversidad biológica, ya que en estas es posible proteger a las especies silvestres de acciones humanas que afectan su sobrevivencia (Simonetti \& Mella 1997). La capacidad de las áreas silvestres protegidas de representar y mantener los elementos de biodiversidad es afectada de manera importante por sus características espaciales, incluyendo tamaño del área protegida, nivel de fragmentación y cercanía a otras áreas protegidas (Williams et al. 2005, Lasky \& Keitt 2013, Durán et al. 2015). En el caso particular de la isla Mocha, su composición, riqueza y abundancia actual de especies parece estar influenciada por el efecto de la actividad antrópica y la alteración histórica del paisaje. Es posible que la distancia a la costa continental también afecte su diversidad de especies, dado que solamente aquellas especies que tienen la capacidad de volar largas distancias podrían tener un recambio poblacional.

Dado que todos los estudios avifaunísticos en la isla han tenido restricciones metodológicas es difícil determinar si la ausencia actual de ciertas especies es consecuencia de la alteración o modificación de los hábitats originales o un artefacto del diseño de muestreo. Por ejemplo, el chirihue (Sicalis luteola) y el jote de cabeza negra (Coragyps atratus), cuya presencia fue documentada por Housse (1924) y Bullock (1935), no fueron observados durante nuestro estudio. Esto es intrigante ya que son especies bastante comunes. Además, el jote de cabeza negra tiene una gran capacidad de desplazamientos y a menudo su presencia está asociada al jote de cabeza colorada. Por otra parte, queda la duda si la virtual ausencia del concón (Strix rufipes), un búho especialista de bosque, se debe a la fuerte degradación del bosque valdiviano o a una falta de un muestreo apropiado (e.g., censos nocturnos).

En términos avifaunísticos la isla Mocha representa un "trozo" continental del sur de Chile. La similitud en la diversidad de hábitats de esta isla con el continente resulta en ensambles similares de aves. Un hábitat que merece mucho más atención en términos faunísticos es el bosque 
valdiviano. Los resultados obtenidos en nuestro estudio solo reflejan los registros en un único punto de conteo, lo cual ciertamente los hace inconcluyentes. Independiente de esto último, nuestros estudio confirma que la Reserva Nacional Isla Mocha no solo constituye un reservorio del bosque valdiviano per se, sino también de la dinámica temporal del ensamble de aves que la habitan. Cabe recalcar que el bosque valdiviano constituye un ecosistema boscoso único a escala global por lo cual su protección y conservación es prioritaria (Armesto et al. 1998, Donoso 1993, Dinerstein et al. 1995).

\section{AGRADECIMIENTOS}

Agradecemos a la Corporación Nacional Forestal (CONAF) por facilitarnos el trabajo en esta Reserva del SNASPE, especialmente al Guardaparque Guillermo Reyes Cabrera, Iván Aranibar Calle (Q.E.P.D) y Francisco Astete Castillo. Parte de estas observaciones fueron realizadas durante el desarrollo del proyecto FONDECYT 1130948.

\section{REFERENCIAS}

Anderson, C., Rozzi, R. 2000. Bird assemblages in the southernmost forests of the world: methodological variations for determining species composition. Anales del Instituto de la Patagonia 28: 89-100.

Armesto, J.J., Rozzi, R., Smith-Ramírez, C., Arroyo, M.T.K. 1998. Conservation targets in South American temperate forests. Science 282: 1271-1272.

Bahamondes, I., Castilla, J.C. 1986. Predation of marine invertebrates by the kelp gull Larus dominicanus in an undisturbed intertidal rocky shore of central Chile. Revista Chilena de Historia Natural 59: 65-72.

Belant, J. 1997. Gulls in urban environments: landscape-level management to reduce conflict. Landscape Urban Planning 38: 245-258.

Bertellotti, M., Yorio, P. 1999. Spatial and temporal patterns in the diet of the Kelp Gull in Patagonia. Condor 101: 790798.

Birdlife International. 2008. Birdlife data zone [en línea].www. birdlife.org [Consulta: 10 mayo 2009].

Brown, C.E, Anderson, C.B., Ippi, S., Sherriffs, M.S, Charlin, R. McGenee, S., Rozzi, R. 2007. The autoecology of the fío-fío (Elaenia Albiceps Lafresnaye \& D'orbigny) in Subantarctic forests of the Cape Horn Biosphere Reserve, Chile. Anales del Instituto de la Patagonia (Chile) 35: 2940.

Bullock, D. 1935. Las aves de la Isla de la Mocha. Revista Chilena de Historia Natural 39: 232-253.

Canevari, O., Castro, G., Salaberry, M., Naranjo, L.G. 2001. Guía de los chorlos y playeros de la región Neotropical. American Bird Conservancy, WWW-US, Humedales para las Américas y Manomet Conservation Science, Asociación Calidris, Santiago de Cali, Colombia. 141 pp.
Cañas, A. 1902. La Mocha: descripción de esta isla. Impreso Imprenta Cervantes. Santiago, Chile.

Conaf (Corporación Nacional Forestal). 2013. CONAF en las Áreas Silvestres Protegidas del Estado: conservando la flora y fauna amenazada (Eds. Cunazza, C., Grimberg, M., De la Maza, M.). Santiago, Chile. 150 pp.

Couve, E., Vidal, C. 2003. Aves de Patagonia, Tierra del Fuego y Península Antártica. Fantástico Sur Birding Ltda. Punta Arenas, Chile. 656 pp.

Copatti, C.E., Dias do Amaral, A., Alles de Moura, C.F. 2013. Aves em ecótono Mata Atlântica-Pampa no sul do Brasil. Ciência e Natura 35: 30-40.

Cursach, J.A., RaU, J.R. 2008. Influencia de las perturbaciones humanas sobre la diversidad del ensamble de aves costeras en el seno de Reloncaví, sur de Chile. Boletín Chileno de Ornitología 14: 92-97.

Cursach, J.A., Rau, J.R, Ojeda, J., Vilugrón, J., Tobar, C., Oyarzún, C., Soto, O., Suazo, C.G. 2011. Diversidad de aves y mamíferos marinos en bahía San Pedro, costa de Purranque, centro-sur de Chile. Gayana 75: 146-154.

Dinerstein, E. 1995. A conservation assesment of the terrestrial ecoregions of Latin America and the Caribbean. WWW Fund \& World Bank, Washington, DC USA.

Donoso, C. 1993. Bosques templados de Chile y Argentina. Editorial Universitaria, Santiago, Chile. 484 pp.

Durán, A.P., Inger, R., Cantú-Salazar, L., Gaston, K.J. 2015. Species richness representation within protected areas is associated with multiple interacting spatial features. Diversity \& Distributions. DOI: 10.1111/ddi.12404

Erazo, S. 1984. Análisis de censos de avifauna realizados en un rodal boscoso de olivillo, Valdivia, Chile. Revista Geográfica de Valparaíso (Chile) 15: 49-71.

EspinosA, L. 1999. Censo neotropical de aves acuáticas 1998. Boletín Chileno de Ornitología 6: 47-52.

EstadES, C.F. 1994. Impacto de la sustitución del bosque natural por plantaciones de Pinus radiata sobre una comunidad de aves en la Octava Región de Chile. Boletín Chileno de Ornitología 1: 8-14.

FeInsinger, P. 2001. Designing field studies for biodiversity conservation. The Nature Conservancy. Island Press, Washington, USA. 2012 pp.

Figueroa, R.A., Corales, E.S. 2004. Summer diet comparison of the American Kestrel (Falco sparverius) and Aplomado Falcon (Falco femoralis) in an agricultural area of Araucanía, southern Chile. Hornero 19: 53-60.

Figueroa, R.A., Quintana, V. 2001. Comunidad invernal de aves en un paisaje agroforestal del centro-sur de Chile. Boletín Chileno de Ornitología 8: 31-35.

Figueroa, R.A., Cerda, J., Tala, C. 2001. Guía de aves dulceacuícolas de Aysén. Servicio Agrícola y Ganadero, Ministerio de Agricultura, Gobierno de Chile. 184 pp.

Gantz, A., Rau. J. 1999. Relación entre el tamaño mínimo de fragmentos boscosos y su riqueza de especies de aves en el sur de Chile. Anales del Museo de Historia Natural de Valparaíso 24: 85-90.

Giaccardi, M., Yorio, P., Lizurume, M.E. 1997. Patrones estacionales de abundancia de la Gaviota Cocinera (Larus dominicanus) en un basural patagónico y sus relaciones con el manejo de residuos urbanos y pesqueros. Ornitología Neotropical 8: 77-84. 
GonzÁlez-Acuña, D., Valenzuela-Dellarossa, G., Barrientos, C., Ardiles, K., Godoy, C., Figueroa, R.A. 2006. Aves del Aeródromo Bernardo O`Higgins de Chillán, Región del Bío-Bío, Chile. Boletín Chileno de Ornitología 12: 15-25.

Goodall, J.D., Johnson, A.W., Philippi, R.A. 1951. Las aves de Chile: su conocimiento y sus costumbres. Tomo II. Platt Establecimientos Gráficos. Buenos Aires, Argentina. 422 pp.

Guicking, D., Mickstein, S., Schlatter, R.P. 1999. Estado de la población reproductiva de fardela blanca (Puffinus creatopus, Coues 1864) en Isla Mocha, Chile. Boletín Chileno de Ornitología 6: 33-35.

Hajek, E., Di Castri, F. 1975. Bioclimatografía de Chile: manual de consulta. Universidad Católica de Chile. Santiago, Chile. 107 pp.

Hinojosa, A., Hodum, P. 2007. Plan nacional para la conservación de la fardela de vientre blanco Puffinus creatopus, Coues 1864, en Chile. CONAF / CONAMA. Santiago, Chile.

Housse, R. 1924. Apuntes de las aves de la Isla Mocha. Revista Chilena de Historia Natural 28: 47-55.

Housse, R. 1925. Adición a los apuntes de las aves de la Isla Mocha. Revista Chilena de Historia Natural 29: 225-227.

Hucke-Gaete, R., Ruiz, J. 2010. Guía de campo de las aves y mamíferos marinos del sur de Chile. Gobierno Regional de los Lagos, Ministerio del Medio Ambiente \& Universidad Austral de Chile. 136 pp.

Hutterer, R. 1994. Island rodents: a new species of Octodon from Isla Mocha, Chile (Mammalia: Octodontidae). Zeitschrift für Saugetierkunde 59: 27-51.

IBARRA-VIDAL, H., KLesSE, M.C. 1994. Nota sobre la fardela blanca (Puffinus creatopus, Coues 1864) (Aves, Procellariidae) de la Isla Mocha, VIII Región, Chile. Comunicaciones del Museo de Historia Natural de Concepción 8: 49-54.

JAKSIC, F.M. 2000. Ecología de comunidades. Ediciones Universidad Católica de Chile. 233 pp.

JaKsic, F.M., FeInsinger, P. 1991. Bird assemblages in temperate forests of North and South America: a comparison of diversity, dynamics, guild structure, and resource use. Revista Chilena de Historia Natural 64: 491-510.

JACKSON, D. 2008. Larvas de Lygirus villosus (Coleoptera: Scarabaeidae) en la dieta de la gaviota cáhuil (Larus maculipennis) (Laridae), en un valle interior de la Región del Maule, Chile. Boletín Chileno de Ornitología 14: 112155.

JACKSON, D., CAMPBELL, R. RoA, C., JACKSON, D. 2013. Implicancias paleoclimáticas y biogeográficas de moluscos terrestres y dulceacuícolas del Holoceno Tardío en isla Mocha, Provincia de Arauco, Chile. Gayana Zoología 77: 83-88.

JiMÉNEZ, J.E. 2000. Effect of sample size, plot size, and counting time on estimates of avian diversity and abundance in a Chilean rainforest. Journal of Field Ornithology 71: 66-87.

Kier, G., Kreft, H., Lee, T.M., Jetz, W., Ibisch, P.L., Nowicki, C., MutKe, J., Barthlott, W. 2009. A global assessment of endemism and species richness across island and mainland regions. Proceedings of the National Academy of Sciences (USA) 106: 9322-9327.

KREBS CJ. 1989, Ecological methodology. Harper \& Row, NY, USA.

Kunkel, G. 1968. Die phanerogamen der Insel La Mocha (Chile). Willdenowia 4: 319-352.
LASKY, J.R., KeITT, T.H. 2013. Reserve size and fragmentation alter community assembly, diversity, and dynamics. American Naturalist 182: 142-160.

Lequesne, C., Meyer, R. 1990. Estudio vegetacional de la isla Mocha. Corporación Nacional Forestal, Ministerio de Agricultura. Los Angeles, Chile. Pp 24.

Lequesne, C., Villagrán, C., Villa, R. 1999. Historia de los bosques relictos de "olivillo" (Aextoxicum punctactum) y mirtáceas de la Isla Mocha, Chile, durante el Holoceno tardío. Revista Chilena de Historia Natural 72: 31-74.

Lizurume, M.E., Yorio, P., Giaccardi, M. 1995. Biología reproductiva de la gaviota capucho café (Larus maculipennis) en Trelew, Patagonia. Hornero 14: 27-32.

López-BARRERA. 2004. Estructura y función en bordes de bosques. Ecosistemas 13: 67-77.

López-Callejas, M.V. 1989. Metodologías de conteo en aves. Flora, Fauna y Áreas Silvestres (FAO/PNUMA) 3: 27-31.

MacArthur, R.H., Wilson, E.O. 1967. The theory of island biogeography. Princeton University Press, NJ, USA. 203 pp.

Martínez, D., GonzÁlez, G. 2005. Las aves de Chile: nueva guía de campo. Ediciones del Naturalista. Santiago, Chile. 620 pp.

Péfaur, J., YÁñEz, J. 1980. Ecología descriptiva de la Isla Mocha (Chile) en relación al poblamiento de los vertebrados. Boletín del Museo Nacional de Historia Natural 37: 103112.

Péfaur, J., Humphrey, P. 1995. Prediction of species richness of birds on austral South American island. Revista de Ecología Latinoamericana 2: 23-35.

Petracci, P.F., La Sala, L.F., Aguerre, G., Pérez, C.H., Acosta, N., Sotelo, M.R., Pamparana, C. 2004. Dieta de la gaviota cocinera (Larus dominicanus) durante el período reproductivo en el estuario de Bahía Blanca, Buenos Aires, Argentina. Hornero 19: 23-28.

PhILIPPI, R.A. 1902. Suplemento a los batraquios chilenos descritos en la Historia Física y Política de Chile de don Claudio Gay. Imprenta de Enrique Blanchard-Chessi, Santiago. $161 \mathrm{pp}$.

Preston, F. 1948. The commonness and rarity of species. Ecology 43: 254-283.

Quilhot, W., Cuellar, M., Díaz, R., Riquelme, F., Rubio, C. 2010. Estudio preliminar de la flora liquénica de Isla Mocha, sur de Chile. Gayana Botánica 67: 206-212.

Remsen, J.V. JR., Cadena, C.D., Jaramillo, A., Nores, M., Pacheco, J.F., Pérez-Emán, J., Robbins, M.B., Stiles, F.G., Stotz, D.F., ZiMMER, K.J. 2013. A classification of the bird species of South America. American Ornithologists' Union. http:// www.museum.lsu.edu/ Remsen/SACCBaseline.

Reyes-Arriagada, R., Campos-Ellwanger, P., Schlatter, R.P. 2009. Avifauna de Isla Guafo. Boletín Chileno de Ornitología 15: 35-43.

Rottmann, J. 1995. Guía de identificación de aves de ambientes acuáticos. Unión de Ornitólogos de Chile, Santiago. 80 pp.

Rozzi, R., Martínez, D.R., Willson, M., Sabag, C. 1996. Avifauna de los bosques templados de Sudamérica. En: Ecología de los bosques nativos de Chile (Eds. Armesto, J.J., Villagrán C., Arroyo, M.T.K.), pp. 135-152. Editorial Universitaria, Santiago, Chile.

Silva, M.P., BastidA, O., Darrieu, C.A. 2000. Ecología trófica de 
la gaviota cocinera (Larus dominicanus) en zonas costeras de la provincia de Buenos Aires. Ornitología Neotropical 11: 331-339.

Silva-Rodríguez, E.A., Ortega-Solís, G.R., JimÉnez, J.E. 2008. Descripción del ensamble de aves en un agroecosistema del sur de chile. Boletín Chileno de Ornitología 14: 81-91.

SutherLAND, W.J. 1996. Ecological census techniques: A handbook. Cambridge University Press, USA. 336 pp.

Simonetti, J.A., Mella, J.E. 1997. Park size and the conservation of Chilean mammals. Revista Chilena de Historia Natural 70: 213-220.

Smith-Ramírez, C. 1993. Los picaflores y su recurso floral en el bosque templado de la isla de Chiloé, Chile. Revista Chilena de Historia Natural 66:65-13.

Verdugo, R. 1988. Reserva Nacional Isla Mocha: un ecosistema insular. CONAF. Concepción, Chile. 8 pp.

Warren, B.H., Simberloff, D., Ricklefs, R.E., Aguilee, R., Condamine, F.L., Gravel, D., Morlon, H., Mouquet,
N., Rosindell, J., Casquet, J., Conti, E., Cornuault, J., Fernández-Palacios, J.M., Hengl, T., Norder, S.J., Rijsdijk, K.F., Sanmartin, I., Strasberg, D., Triantis, K.A., Valente, L.M., Whittaker, R.J., Gillespie, R.G., Emerson, B.C., Thebaud, C. 2015. Islands as model systems in ecology and evolution: Prospects fifty years after MacArthur-Wilson. Ecology Letters. doi: 10.1111/ ele. 12398

Whittaker, R. J., FernÁndez-Palacios, J.M. 2007. Island biogeography: Ecology, evolution, and conservation. Second Edition. Oxford University Press, UK. 401 pp.

Williams, J.C., ReVelle, C.S., Levin, S.A. 2005. Spatial attributes and reserve design models: a review. Environmental Modeling \& Assessment 10: 163-181.

Willson, M.F., De Santo, T.L., Sabag, C., Armesto, J.J. 1994. Avian communities of fragmented south-temperate rainforests in Chile. Conservation Biology 8: 508-520.

Anexo 1. Listado de especies de aves presentes en la Reserva Nacional Isla Mocha según la literatura. Fuentes: Hs = Housse (1924, 1925), Bk = Bullock (1935), P\&Y = Péfaur \& Yáñez (1995), EE = este estudio. Estado de conservación, Gl = Glade $(1993):$ EP = en peligro, VU = vulnerable, $\mathrm{R}=$ Rara, $\mathrm{IC}=$ inadecuadamente conocida; $\mathrm{BL}=$ Birdlife International (2008): EP = en peligro, VU = vulnerable. Hábitos (HA): $\mathrm{A}=$ acuática, $\mathrm{T}=$ terrestre, $\mathrm{d}=$ dulceacuícola, $\mathrm{m}=$ marina, $\mathrm{p}=$ praderas abiertas, $\mathrm{b}=$ bosque y matorrales, $\mathrm{pa}=$ praderas arboladas, $\mathrm{u}=$ áreas urbanizadas (Fuentes: Rottmann 1995, Figueroa et al. 2001, Couve \& Vidal 2003). / List of bird species present in Isla Mocha according to the literature. Sources: Hs = Housse $(1924,1925)$, Bk = Bullock (1935), P \& Y = Péfaur \& Yáñez (1995), EE = this study. Conservation status (EC), $\mathrm{GL}=$ Glade (1993): $\mathrm{EP}=$ endangered, $\mathrm{VU}=$ vulnerable, $\mathrm{R}=\mathrm{Rare}, \mathrm{IC}=$ inadequately known; $\mathrm{BL}=\mathrm{Birdlife}$ International (2008), $\mathrm{EP}=$ endangered, $\mathrm{VU}=$ vulnerable. Habits $(\mathrm{HAB}): \mathrm{A}=$ aquatic, $\mathrm{T}=$ terrestrial, $\mathrm{d}=$ freshwater, $\mathrm{m}=$ marine, $\mathrm{p}=$ open prairie, $\mathrm{b}=$ forest and bushes, $\mathrm{pa}=$ prairie with trees, $\mathrm{u}=$ urban areas (References: Rottmann 1995, Figueroa et al. 2001, Couve \& Vidal 2003).

\begin{tabular}{|c|c|c|c|c|c|c|c|}
\hline \multirow[b]{2}{*}{ ESPECIES } & \multirow[b]{2}{*}{$\mathrm{H}$} & \multirow[b]{2}{*}{$\mathrm{B}$} & \multirow[b]{2}{*}{$\mathrm{P} \& \mathrm{H}$} & \multirow[b]{2}{*}{$\mathrm{EE}$} & \multicolumn{2}{|c|}{ EC } & \multirow[b]{2}{*}{$\mathrm{HAB}$} \\
\hline & & & & & $\mathrm{G}$ & BL & \\
\hline \multicolumn{8}{|l|}{ Anseriformes } \\
\hline Pato colorado (Anas cyanoptera) & $\mathrm{X}$ & $\mathrm{X}$ & & $\mathrm{X}$ & & & A, d \\
\hline Pato jergón chico (Anas flavirostris) & $\mathrm{X}$ & & & & & & A, d \\
\hline Pato jergón grande (Anas georgica) & & $\mathrm{X}$ & & $\mathrm{X}$ & & & A, d \\
\hline Pato real (Anas sibilatrix) & & & & $\mathrm{X}$ & & & A, d \\
\hline Podicipediformes & & & & & & & . \\
\hline Pimpollo (Rollandia rolland) & $\mathrm{X}$ & $\mathrm{X}$ & & $\mathrm{X}$ & & & A, d \\
\hline Picurio (Podilymbus podiceps) & & $\mathrm{X}$ & & & & & $A, d$ \\
\hline Blanquillo (Podiceps occipitalis) & & & & $\mathrm{X}$ & & & A, d \\
\hline \multicolumn{8}{|l|}{ Sphenisciformes } \\
\hline Pingüino de Humboldt (Spheniscus humboldti) & $\mathrm{X}$ & & & & & VU & $\mathrm{A}, \mathrm{m}$ \\
\hline Pingüino de magallanes (Spheniscus magellanicus) & $\mathrm{X}$ & & & & & & $\mathrm{A}, \mathrm{m}$ \\
\hline \multicolumn{8}{|l|}{ Procellariiformes } \\
\hline Albatros de ceja negra (Thalassarche melanophrys) & $\mathrm{X}$ & $\mathrm{X}$ & & & & EN & $\mathrm{A}, \mathrm{m}$ \\
\hline Albatros errante (Diomedaea exulans) & $\mathrm{X}$ & $\mathrm{X}$ & & & & VU & $\mathrm{A}, \mathrm{m}$ \\
\hline Golondrina de mar (Oceanites sp.) & $\mathrm{X}$ & $\mathrm{X}$ & & & & & $\mathrm{A}, \mathrm{m}$ \\
\hline Fardela blanca (Ardenna creatopus) & $\mathrm{X}$ & $\mathrm{X}$ & $\mathrm{X}$ & & $\mathrm{V}$ & VU & $\mathrm{A}, \mathrm{m}$ \\
\hline Fardela negra (Ardenna griseus) & & $\mathrm{X}$ & & & & & $\mathrm{A}, \mathrm{m}$ \\
\hline Fardela negra grande (Procellaria aequinoctialis) & $\mathrm{X}$ & & & & & VU & $\mathrm{A}, \mathrm{m}$ \\
\hline Pato yunco (Pelecanoides garnotii) & $\mathrm{X}$ & $\mathrm{X}$ & & & $\mathrm{V}$ & EN & $\mathrm{A}, \mathrm{m}$ \\
\hline Petrel moteado (Daption capensis) & $\mathrm{X}$ & $\mathrm{X}$ & & & & & $\mathrm{A}, \mathrm{m}$ \\
\hline Petrel plateado (Fulmarus glaciaroides) & $\mathrm{X}$ & $\mathrm{X}$ & & & & & $\mathrm{A}, \mathrm{m}$ \\
\hline \multicolumn{8}{|l|}{ Suliformes } \\
\hline Cormorán imperial (Phalacrocorax atriceps) & & $\mathrm{X}$ & $\mathrm{X}$ & $\mathrm{X}$ & & & $\mathrm{A}, \mathrm{m}$ \\
\hline
\end{tabular}




\begin{tabular}{|c|c|c|c|c|c|c|c|}
\hline \multirow[b]{2}{*}{ ESPECIES } & \multirow[b]{2}{*}{$\mathrm{H}$} & \multirow[b]{2}{*}{$\mathrm{B}$} & \multirow[b]{2}{*}{$\mathrm{P} \& \mathrm{H}$} & \multirow[b]{2}{*}{$\mathrm{EE}$} & \multicolumn{2}{|c|}{$\mathrm{EC}$} & \multirow[b]{2}{*}{ HAB } \\
\hline & & & & & $\mathrm{G}$ & $\mathrm{BL}$ & \\
\hline Guanay (Phalacrocorax bouganvillii) & $\mathrm{X}$ & $\mathrm{X}$ & $\mathrm{X}$ & & $\mathrm{V}$ & & $\mathrm{A}, \mathrm{m}$ \\
\hline Lile (Phalacrocorax gaimardi) & $\mathrm{X}$ & $\mathrm{X}$ & & $\mathrm{X}$ & $\mathrm{IC}$ & & $\mathrm{A}, \mathrm{m}$ \\
\hline Yeco (Phalacrocorax olivaceus) & $\mathrm{X}$ & $\mathrm{X}$ & & $\mathrm{X}$ & & & $\mathrm{A}, \mathrm{m}, \mathrm{d}$ \\
\hline Piquero (Sula variegata) & $\mathrm{X}$ & $\mathrm{X}$ & & $\mathrm{X}$ & $\mathrm{IC}$ & & $\mathrm{A}, \mathrm{m}$ \\
\hline \multicolumn{8}{|l|}{ Pelecaniformes } \\
\hline Pelicano (Pelecanus thagus) & $\mathrm{X}$ & $\mathrm{X}$ & & $\mathrm{X}$ & & & $\mathrm{A}, \mathrm{m}, \mathrm{d}$ \\
\hline Garza boyera (Bubulcus ibis) & & & & $\mathrm{X}$ & & & d \\
\hline Huairavo (Nycticorax nycticorax) & $X$ & $\mathrm{X}$ & & $\mathrm{X}$ & & & A, d \\
\hline Bandurria (Theristicus melanopis) & $X$ & $\mathrm{X}$ & & $X$ & & & $\mathrm{~T}, \mathrm{p}$ \\
\hline \multicolumn{8}{|l|}{ Cathartiformes } \\
\hline Jote de cabeza negra (Coragyps atratus) & $\mathrm{X}$ & $\mathrm{X}$ & & & & & $\mathrm{T}, \mathrm{p}, \mathrm{b}$ \\
\hline Jote de cabeza colorada (Cathartes aura) & $\mathrm{X}$ & & $\mathrm{X}$ & $\mathrm{X}$ & & & $\mathrm{T}, \mathrm{p}$ \\
\hline \multicolumn{8}{|l|}{ Accipitriformes } \\
\hline Aguilucho (Geranoaetus polyosoma) & $\mathrm{X}$ & $\mathrm{X}$ & & $\mathrm{X}$ & & & $\mathrm{T}, \mathrm{p}, \mathrm{m}, \mathrm{b}$ \\
\hline Bailarín (Elanus leucurus) & $\mathrm{X}$ & $\mathrm{X}$ & & $\mathrm{X}$ & & & $\mathrm{T}, \mathrm{p}$ \\
\hline Peuquito (Accipiter bicolor)* & $\mathrm{X}$ & $\mathrm{X}$ & & & $\mathrm{R}$ & & $\mathrm{T}, \mathrm{b}$ \\
\hline Peuco (Parabuteo unicinctus) & $X$ & $\mathrm{X}$ & & & & & $\mathrm{T}, \mathrm{p}, \mathrm{b}$ \\
\hline \multicolumn{8}{|l|}{ Falconiformes } \\
\hline Cernícalo (Falco sparverius) & $\mathrm{X}$ & $\mathrm{X}$ & & $\mathrm{X}$ & & & $\mathrm{T}, \mathrm{p}$ \\
\hline Halcón perdiguero (Falco femoralis) & $\mathrm{X}$ & & & $\mathrm{X}$ & & & $\mathrm{T}, \mathrm{p}$ \\
\hline Halcón peregrino (Falco peregrinus) & $X$ & $X$ & & & EP & & $\mathrm{T}, \mathrm{p}$ \\
\hline Tiuque (Milvago chimango) & & $\mathrm{X}$ & & $\mathrm{X}$ & & & $\mathrm{T}, \mathrm{p}, \mathrm{b}$ \\
\hline Traro (Caracara plancus) & & $\mathrm{X}$ & & & & & $\mathrm{T}, \mathrm{p}, \mathrm{b}$ \\
\hline \multicolumn{8}{|l|}{ Phoenicopteriformes } \\
\hline Flamenco chileno (Phoenicopterus chilensis) & & $\mathrm{X}$ & & & $\mathrm{V}$ & & A, d \\
\hline \multicolumn{8}{|l|}{ Gruiformes } \\
\hline Pidén (Pardirallus sanguinolentus) & & $\mathrm{X}$ & & & & & A, d \\
\hline Tagua (Fulica rufifrons) & $\mathrm{X}$ & $\mathrm{X}$ & & & & & A, d \\
\hline Tagüita (Porphyriops melanops) & $\mathrm{X}$ & $\mathrm{X}$ & & & & & A, d \\
\hline \multicolumn{8}{|l|}{ Charadriiformes } \\
\hline Gaviota cáhuil (Chroicocephalus maculipennis) & $\mathrm{X}$ & $\mathrm{X}$ & & $\mathrm{X}$ & & & $\mathrm{A}, \mathrm{m}, \mathrm{d}$ \\
\hline Gaviota dominicana (Larus dominicanus) & $\mathrm{X}$ & $\mathrm{X}$ & $\mathrm{X}$ & $\mathrm{X}$ & & & A, m, d \\
\hline Salteador (Stercorarius chilensis) & $\mathrm{X}$ & $\mathrm{X}$ & & $\mathrm{X}$ & & & $\mathrm{A}, \mathrm{m}$ \\
\hline Chorlo de doble collar (Charadrius falcklandicus) & $X$ & $\mathrm{X}$ & & & & & $\mathrm{A}, \mathrm{m}, \mathrm{d}$ \\
\hline Chorlo nevado (Charadrius nivosus) & & $\mathrm{X}$ & & $X$ & & & A, m, d \\
\hline Playero de Baird (Calidris bairdii) & & $\mathrm{X}$ & & $\mathrm{X}$ & & & A, m, d \\
\hline Pollo de mar (Charadrius cantianus)** & $\mathrm{X}$ & & & & & & \\
\hline Queltehue (Vanellus chilensis) & $X$ & $\mathrm{X}$ & & $\mathrm{X}$ & & & T, p. A, d \\
\hline Perrito (Himantopus mexicanus) & & & & $\mathrm{X}$ & & & A, d \\
\hline Chorlo dorado (Pluvialis dominica) & & $\mathrm{X}$ & & & & & A, d \\
\hline Pilpilén (Haematopus palliatus) & $\mathrm{X}$ & $\mathrm{X}$ & $\mathrm{X}$ & $\mathrm{X}$ & & & A, m, d \\
\hline Pilpilén negro (Haematopus ater) & $\mathrm{X}$ & $X$ & & $X$ & & & $\mathrm{~A}, \mathrm{~m}$ \\
\hline Playero blanco (Calidris alba) & & $\mathrm{X}$ & & & & & A, m, d \\
\hline Playero de las rompientes (Aphriza virgata) & & $\mathrm{X}$ & & $\mathrm{X}$ & & & $\mathrm{A}, \mathrm{m}$ \\
\hline Playero vuelve piedras (Arenaria interpres) & $X$ & $\mathrm{X}$ & & $\mathrm{X}$ & & & $\mathrm{A}, \mathrm{m}$ \\
\hline Becacina (Gallinago paraguaiae) & $\mathrm{X}$ & $\mathrm{X}$ & & $\mathrm{X}$ & $\mathrm{V}$ & & A, d \\
\hline Zarapito (Numenius phaeopus) & & $\mathrm{X}$ & $\mathrm{X}$ & $\mathrm{X}$ & & & $\mathrm{A}, \mathrm{m}, \mathrm{d}$ \\
\hline Playero semipalmado (Calidris pusilla) & $\mathrm{X}$ & $\mathrm{X}$ & & & & & $\mathrm{A}, \mathrm{m}$ \\
\hline
\end{tabular}




\begin{tabular}{|c|c|c|c|c|c|c|c|}
\hline \multirow[b]{2}{*}{ ESPECIES } & \multirow[b]{2}{*}{$\mathrm{H}$} & \multirow[b]{2}{*}{$\mathrm{B}$} & \multirow[b]{2}{*}{$\mathrm{P} \& \mathrm{H}$} & \multirow[b]{2}{*}{ EE } & \multicolumn{2}{|c|}{$\mathrm{EC}$} & \multirow[b]{2}{*}{ HAB } \\
\hline & & & & & $\mathrm{G}$ & $\mathrm{BL}$ & \\
\hline \multicolumn{8}{|l|}{ Caprimulgiformes } \\
\hline Gallina ciega (Systellura longirostris) & $\mathrm{X}$ & $\mathrm{X}$ & & & & & $\mathrm{T}, \mathrm{m}, \mathrm{b}$ \\
\hline \multicolumn{8}{|l|}{ Columbiformes } \\
\hline Torcaza (Patagioenas araucana) & $\mathrm{X}$ & $\mathrm{X}$ & $\mathrm{X}$ & $\mathrm{X}$ & $\mathrm{V}$ & & $\mathrm{T}, \mathrm{b}, \mathrm{pa}$ \\
\hline Tórtola (Zenaida auriculata) & & & & $\mathrm{X}$ & & & $\mathrm{T}, \mathrm{b}, \mathrm{pa}$ \\
\hline Paloma (Columba livia) & & & & $\mathrm{X}$ & & & $\mathrm{T}, \mathrm{u}$ \\
\hline \multicolumn{8}{|l|}{ Psittaciformes } \\
\hline Choroy (Enicognathus leptorhynchus) & $\mathrm{X}$ & $\mathrm{X}$ & $\mathrm{X}$ & & $\mathrm{V}$ & & $\mathrm{T}, \mathrm{b}, \mathrm{pa}$ \\
\hline \multicolumn{8}{|l|}{ Strigiformes } \\
\hline Lechuza (Tyto alba) & $\mathrm{X}$ & $\mathrm{X}$ & & & & & $\mathrm{T}, \mathrm{p}, \mathrm{b}, \mathrm{u}$ \\
\hline Nuco (Asio flammeus) & & $\mathrm{X}$ & & & $\mathrm{IC}$ & & $\mathrm{T}, \mathrm{p}$ \\
\hline \multicolumn{8}{|l|}{ Apodiformes } \\
\hline Picaflor chico (Sephanoides sephaniodes) & $\mathrm{X}$ & $\mathrm{X}$ & $\mathrm{X}$ & $\mathrm{X}$ & & & $\mathrm{T}, \mathrm{b}, \mathrm{pa}$ \\
\hline \multicolumn{8}{|l|}{ Passeriformes } \\
\hline Cometocino patagónico (Phrygilus patagonicus) & & $\mathrm{X}$ & $\mathrm{X}$ & $\mathrm{X}$ & & & $\mathrm{T}, \mathrm{b}, \mathrm{pa}$ \\
\hline Chincol (Zonotrichia capensis) & $\mathrm{X}$ & $\mathrm{X}$ & $\mathrm{X}$ & $\mathrm{X}$ & & & $\mathrm{T}, \mathrm{b}, \mathrm{pa}$ \\
\hline Chirihue (Sicalis luteola) & $\mathrm{X}$ & $\mathrm{X}$ & & $\mathrm{X}$ & & & $\mathrm{T}, \mathrm{p}$ \\
\hline Cometocino de gay (Phrygilus gayi) & $\mathrm{X}$ & & & $\mathrm{X}$ & & & $\mathrm{T}, \mathrm{p}$ \\
\hline Diuca (Diuca diuca) & $\mathrm{X}$ & $\mathrm{X}$ & & $\mathrm{X}$ & & & $\mathrm{T}, \mathrm{p}$ \\
\hline Jilguero (Spinus barbatus) & $\mathrm{X}$ & $\mathrm{X}$ & $\mathrm{X}$ & $\mathrm{X}$ & & & $\mathrm{T}, \mathrm{b}, \mathrm{pa}$ \\
\hline Minero (Geositta cunicularia) & $\mathrm{X}$ & $\mathrm{X}$ & & $\mathrm{X}$ & & & $\mathrm{T}, \mathrm{p}$ \\
\hline Churrete (Cinclodes patagonicus) & & $\mathrm{X}$ & & $\mathrm{X}$ & & & $A, d$ \\
\hline Colilarga del sur (Sylviorthorhynchus desmursii) & $\mathrm{X}$ & $\mathrm{X}$ & & $\mathrm{X}$ & & & $\mathrm{T}, \mathrm{b}$ \\
\hline Churrete acanelado (Cinclodes fuscus) & & & & $X ?$ & & & A, d \\
\hline Churrete costero (Cinclodes nigrofumosus) & $\mathrm{X}$ & $\mathrm{X}$ & & & & & $\mathrm{A}, \mathrm{m}$ \\
\hline Tijeral (Leptasthenura aegithaloides) & & $\mathrm{X}$ & & & & & $\mathrm{T}, \mathrm{pa}$ \\
\hline Golondrina chilena (Tachycineta meyeni) & $\mathrm{X}$ & $\mathrm{X}$ & & $\mathrm{X}$ & & & $\mathrm{T}, \mathrm{b}, \mathrm{pa}$ \\
\hline Bailarín chico (Anthus correndera) & $\mathrm{X}$ & $\mathrm{X}$ & & $\mathrm{X}$ & & & $\mathrm{T}, \mathrm{p}$ \\
\hline Gorrión (Passer domesticus) & & & & $\mathrm{X}$ & & & $\mathrm{T}, \mathrm{u}$ \\
\hline Chucao (Scelorchilus rubecula) & $\mathrm{X}$ & $\mathrm{X}$ & $\mathrm{X}$ & $\mathrm{X}$ & & & $\mathrm{T}, \mathrm{b}$ \\
\hline Churrín de la mocha (Eugralla paradoxa) & $\mathrm{X}$ & $\mathrm{X}$ & $\mathrm{X}$ & $\mathrm{X}$ & & & $\mathrm{T}, \mathrm{b}$ \\
\hline Churrín del Sur (Scytalopus magellanicus) & $\mathrm{X}$ & $\mathrm{X}$ & & $\mathrm{X}$ & & & $\mathrm{T}, \mathrm{b}$ \\
\hline Hued-hued del Sur (Pteroptochos tarnii) & & & & $\mathrm{X}$ & & & $\mathrm{T}, \mathrm{b}$ \\
\hline Chercán (Troglodytes aedon) & & & & $\mathrm{X}$ & & & $\mathrm{T}, \mathrm{b}, \mathrm{pa}$ \\
\hline Chercán de las vegas (Cistothorus platensis) & $\mathrm{X}$ & $\mathrm{X}$ & $\mathrm{X}$ & $\mathrm{X}$ & & & $A, d$ \\
\hline Cachudito (Anairetes parulus) & $\mathrm{X}$ & $\mathrm{X}$ & & $\mathrm{X}$ & & & $\mathrm{T}, \mathrm{b}, \mathrm{pa}$ \\
\hline Diucón (Xolmis pyrope) & $\mathrm{X}$ & $\mathrm{X}$ & & $\mathrm{X}$ & & & $\mathrm{T}, \mathrm{b}, \mathrm{pa}$ \\
\hline Dormilona tontita (Muscisaxicola macloviana) & $\mathrm{X}$ & $\mathrm{X}$ & & & & & $\mathrm{T}, \mathrm{pa}$ \\
\hline Fío-fío (Elaenia albiceps) & & $\mathrm{X}$ & & $\mathrm{X}$ & & & $\mathrm{T}, \mathrm{b}, \mathrm{pa}$ \\
\hline Rayadito (Aphrastura spinicauda) & $\mathrm{X}$ & $\mathrm{X}$ & & $\mathrm{X}$ & & & $\mathrm{T}, \mathrm{b}$ \\
\hline Rara (Phytotoma rara) & $\mathrm{X}$ & $\mathrm{X}$ & & $\mathrm{X}$ & & & $\mathrm{T}, \mathrm{b}$ \\
\hline Tordo (Curaeus curaeus) & $\mathrm{X}$ & $\mathrm{X}$ & & & & & $\mathrm{T}, \mathrm{b}, \mathrm{pa}$ \\
\hline Trile (Agelasticus thilius) & $\mathrm{X}$ & $\mathrm{X}$ & & & & & $A, d$ \\
\hline Zorzal (Turdus falklandii mochae) & $\mathrm{X}$ & $\mathrm{X}$ & & $\mathrm{X}$ & & & $\mathrm{T}, \mathrm{b}, \mathrm{pa}$ \\
\hline Viudita (Colorhamphus parvirostris) & & & & $\mathrm{X}$ & & & $\mathrm{T}, \mathrm{b}, \mathrm{pa}$ \\
\hline
\end{tabular}

Recibido: 04.05.2017

Aceptado: 23.05.2018 